\title{
Longitudinal versus Lateral Estuarine Dynamics and Their Role in Tidal Stratification Patterns in Lower South San Francisco \\ Bay
}

\author{
Olivia Hoang ${ }^{1}$, Mark Stacey ${ }^{1}$, David Senn ${ }^{2}$, Rusty Holleman ${ }^{3}$, Lissa MacVean ${ }^{4}$ \\ ${ }^{1}$ University of California, Berkeley \\ ${ }^{2}$ San Francisco Estuary Institute \\ ${ }^{3}$ University of California, Davis \\ ${ }^{4}$ University of Michigan
}

\section{Key Points:}

- Vertical stratification in shoal-channel estuary characterized by strong intratidal variability

- Lateral circulation is key driver of intratidal stratification dynamics at tide transitions

- Timing and magnitude of longitudinal straining and advection, lateral straining and advection set intratidal vertical stratification dynamics

This is the author manuscript accepted for publication and has undergone full peer review but has not been through the copyediting, typesetting, pagination and proofreading process, which may leorespondipg author: Olivia Hoang oliviahoangaberkeley edu as doi: 10.1029/2019JC014980

This article is protected by copyright. All rights reserved. 


\begin{abstract}
The dynamics of shoal-channel estuaries require consideration of lateral gradients and transport, which can create significant intratidal variability in stratification and circulation. When the shoal-channel system is strongly coupled by tidal exchange with mudflats, marshes or other habitats, the gradients driving intratidal stratification variations are expected to intensify. To examine this dynamic, hydrodynamic data was collected from January 27, 2017 - February 10, 2017 in Lower South San Francisco Bay, a small subembayment fringed by extensive shallow vegetated habitats. During this deployment, salinity variations were captured through instrumentation of 6 stations (arrayed longitudinally and laterally) allowing for mechanisms of stratification creation and destruction to be calculated directly and compared with observed time variability of stratification at the central station. We present observation-based calculations of longitudinal straining, longitudinal advection, lateral straining, and lateral advection. The time dependence of stratification was observed directly and calculated by summing measured longitudinal and lateral mechanisms.
\end{abstract}

We found that the stratification dynamics switch between being longitudinally dominated during the middle of ebb and flood tides to being laterally dominated during the tidal transitions. This variability is driven by the interplay between tidally-variable lateral density gradients and turbulent mixing. Relatively constant along-estuary density gradients are differentially advected during flood and ebb tides, resulting in maximal lateral density gradients around tidal transitions. Simultaneous decrease in turbulent mixing at slack tides allows lateral density-driven exchange to stratify the estuary channel at the slack after flood. At the end of ebb, barotropic forcing drives negatively buoyant shoal waters towards the channel.

\title{
Plain Language Summary
}

San Francisco Bay sits within a highly urbanized area. The dense population creates large wastewater effluent resulting in high nutrient levels. Scientists wonder why there have not been annual phytoplankton blooms like observed in other estuaries with lower nutrient levels. Some have hypothesized it is due to high turbidity levels and tidal breakdown of stratification creating nonideal environments for phytoplankton growth. However, decadal-trends show that the estuary is becoming less turbid, and with changes in climate patterns, there is potential for persistent stratification.

We observed development of stratification over the ebb tide and destratification in two distinct events as the tide reverses over the flood tide. At the reversal of the tides, water in the shoals exchange with the water in the channel creating a pulse of salty water to the channel at the ebb to flood transition and a pulse of fresh water at the flood to the ebb transition. Destratification occurs in the early flood tide due to a pulse of saline water received from the shoals then due to the advection of less stratified water being pulled to the center channel of the estuary. Finally, stratification is destroyed completely due to longitudinal straining and turbulent mixing.

\section{Introduction}

The dynamics of estuaries are governed by the interaction of freshwater buoyancy inputs, tides, and turbulent mixing produced by the tidal forcing [Geyer and MacCready, 2014]. The balance between these processes establish the strength and variability of vertical mixing, stratification, lateral circulation and transport. Each of these physical components influences the estuarine ecosystem, by defining vertical and lateral fluxes that exchange phytoplankton, oxygen, and nutrients between pelagic and near-benthic regions [Lucas et al., 1999]. When the shoal-channel system is bounded by shallow vegetated 
perimeter habitats, both physical and biological variability in the system may be enhanced by the proximity of habitat variations.

Starting with Simpson (1990), the estuarine community has established the importance of longitudinal straining to the creation and destruction of stratification and estuarine circulation [Jay and Smith, 1990; Nepf and Geyer, 1996; Geyer et al., 2000; Scully and Geyer, 2012]. Longitudinal gradients of salinity, usually created by buoyancy inputs from specific freshwater sources, but also potentially from direct precipitation into perimeter habitats and evaporation, are established and maintained to become key physical drivers for local longitudinal circulation. The buoyant forcing in estuaries works to create stratification and is opposed by turbulent mixing which works to homogenize the water column. Simpson's goal was to create a simple model that predicted the onset and break down of stratification for regions with significant freshwater input. A simple longitudinal balance to describe the competition between straining and mixing can be framed as:

$$
\frac{\partial}{\partial t} \frac{\partial S}{\partial z}+\underset{\text { Longitudinal Straining }}{\frac{\partial u}{\partial z} \frac{\partial S}{\partial x}}=\underbrace{\frac{\partial}{\partial z} K\left(\frac{\partial^{2} S}{\partial z^{2}}\right)}_{\text {Turbulent Mixing }}
$$

During the ebb tide, if longitudinal gradients are sufficiently strong, straining overcomes turbulent mixing to create stable stratification. Any stratification that exists at the end of the ebb tide is gradually eliminated by the reversed straining during the flood tide, potentially leading to unstratified conditions and "over-straining" to produce convective instabilities [Nepf and Geyer, 1996]. The strain induced periodic stratification (SIPS) is asymmetric between ebb and flood tides due to the contribution of turbulent mixing (right side of (1)), which is always acting to reduce stratification. This asymmetry in stratification also feeds back into the turbulence and strengthens the ebb-flood asymmetry in mixing, with a more constrained near-bottom turbulent boundary layer on ebbs and more energetic and extensive mixing on the floods.

A scaling of this competition between straining and mixing, which determines the degree to which periodic stratification can develop, results in the Simpson number:

$$
S i=\frac{g \beta \frac{\partial S}{\partial x} H^{2}}{u_{*}^{2}}
$$

where $\beta$ is the coefficient of saline contractivity, $H$ represents the local depth, and $u_{*}$ is a friction velocity based on tidal flows and forcing. For small values of $\mathrm{Si}$, the longitudinal density gradient is not strong enough to overcome turbulent mixing and the water column remains unstratified throughout the tidal cycle; as $S i$ increases, conditions will transition to periodic, and eventually persistent, stratification of increasing magnitude.

The role of longitudinal straining in setting estuarine stratification and circulation is now widely established, but recent work has expanded consideration to the role of lateral dynamics in defining estuarine stratification. Lateral effects on stratification have been observed on a tidal time scale in North San Francisco Bay [Lacy et al., 2003], the Hudson River estuary [Scully and Geyer, 2012], and the German Wadden Sea [Becherer et al., 2014]. These observations were found to deviate from the traditionally assumed longitudinally driven tidal straining model developed by Simpson et al. 1990 proving the threedimensionality of estuarine systems and thus highlighting the importance of understanding lateral transport processes. Observations in Northern San Francisco Bay found deviations in stratification patterns from the classically explained longitudinally-strained SIPS conditions occurred during low tidal energy periods when the tide transitioned. During tidal phases with the largest tidal velocities in the channel, turbulence created a barrier preventing lateral exchanges between the shoal and the channel [Lacy et al., 2003]. When the turbulence decreased, lateral exchange was able to form, driven by baroclinic forcing.

The lateral velocity, $v$, is typically an order of magnitude smaller than the longitudinal velocity, $u$ [Lerczak and Geyer, 2004], and was therefore frequently neglected in anal- 
ysis of estuarine stratification dynamics. However, if the lateral salinity gradient is large, lateral straining could become a significant contributor to the tidal pattern of stratification.

$$
\frac{\partial}{\partial t} \frac{\partial S}{\partial z}+\underset{\text { Longitudinal Straining }}{\frac{\partial u}{\partial z} \frac{\partial S}{\partial x}}+\frac{\partial v \frac{\partial S}{\partial z} \frac{\partial}{\partial y}}{\text { Lateral Straining }}=\underbrace{\frac{\partial}{\partial z} K\left(\frac{\partial^{2} S}{\partial z^{2}}\right)}_{\text {Turbulent Mixing }}
$$

Dynamically, we consider the structure and magnitude of the lateral density-driven flow based on a balance between the baroclinic pressure gradient and the vertical stress divergence, parameterized with a constant vertical viscosity. Including a constraint of mass conservation, and an associated compensating barotropic pressure gradient, this balance results in a bi-directional lateral velocity profile described by the following equation:

$$
v(z)=\frac{1}{v_{T}} g \beta \frac{\partial S}{\partial y}\left(\frac{H z^{2}}{2}-\frac{z^{3}}{6}+\text { constant }\right)
$$

where $v$ is the lateral velocity at a given depth, $z, v_{T}$ is the turbulent viscosity that is scaled with the tidal velocity, $g$ is the acceleration due to gravity, and $y$ is in the lateral, cross-channel direction. As shown (4), when the turbulent viscosity is large, it inhibits the development of lateral exchange [Lacy et al., 2003]. Therefore, lateral exchange is more likely to occur at the transition periods between the tides when the tidal velocity and turbulent mixing are at a minimum.

Lateral density gradients that drive lateral circulation could be created by direct perimeter inputs of freshwater or by differential advection of the longitudinal salinity gradient. Considering a single tidal component, the depth-averaged (tidal) velocity in the channel and shoal can be represented as:

$$
u_{\text {channel }}=A \sin (\omega t), u_{\text {shoal }}=a \sin (\omega t+\phi)
$$

where $A$ is the amplitude of the tidal velocity in the channel, $a$ is the amplitude of the tidal velocity in the shoal and, based on the depth-difference, $A>a$ [Huzzey and Brubaker, 1988; Lerczak and Geyer, 2004]. To leading order, the tidal variability of depth-averaged salinity at a location is set by tidal advection of the longitudinal salinity gradient $\left(\frac{\partial S}{\partial t}=\right.$ $-u \frac{\partial S}{\partial x}$ ) such that we arrive at the following expression for the time variability of the lateral salinity gradient:

$$
\frac{\partial S}{\partial y}=\frac{S_{\text {shoal }}-S_{\text {channel }}}{L_{y}}=\frac{\partial S}{\partial x} \frac{1}{\omega L_{y}} \cos (\omega t)(a-A)
$$

where $L_{y}$ is a representative lateral distance (width of the transition between channel and shoal).

The lateral shear in the longitudinal velocity causes lateral density gradients to be created over both the ebb and flood tides, but with opposite signs on each tidal phase. By the end of the ebb tide, the lateral shear in the longitudinal velocity results in a lateral density gradient in which the shoal density is greater than the density in the channel. During the flood tide, the reverse density gradient is created in which the shoals are fresher than the channel. This sets up a lateral density gradient that can drive a baroclinically driven lateral exchange [Lerczak and Geyer, 2004]. The goal of this paper is to determine the role of longitudinal and lateral dynamics in regulating vertical stratification dynamics in Lower South San Francisco Bay, a partially stratified estuary which has significant lateral density gradients. With observations of salinity gradients in the lateral and longitudinal direction, we will decompose tidal variability of the physical dynamics that creates and destroys stratification.

\section{Methods}

\subsection{Site Description}

San Francisco Bay is a meso-tidal estuary characterized by strong diurnal inequalities that vary with the spring-neap cycle. This paper focuses on a sub-estuary of San 

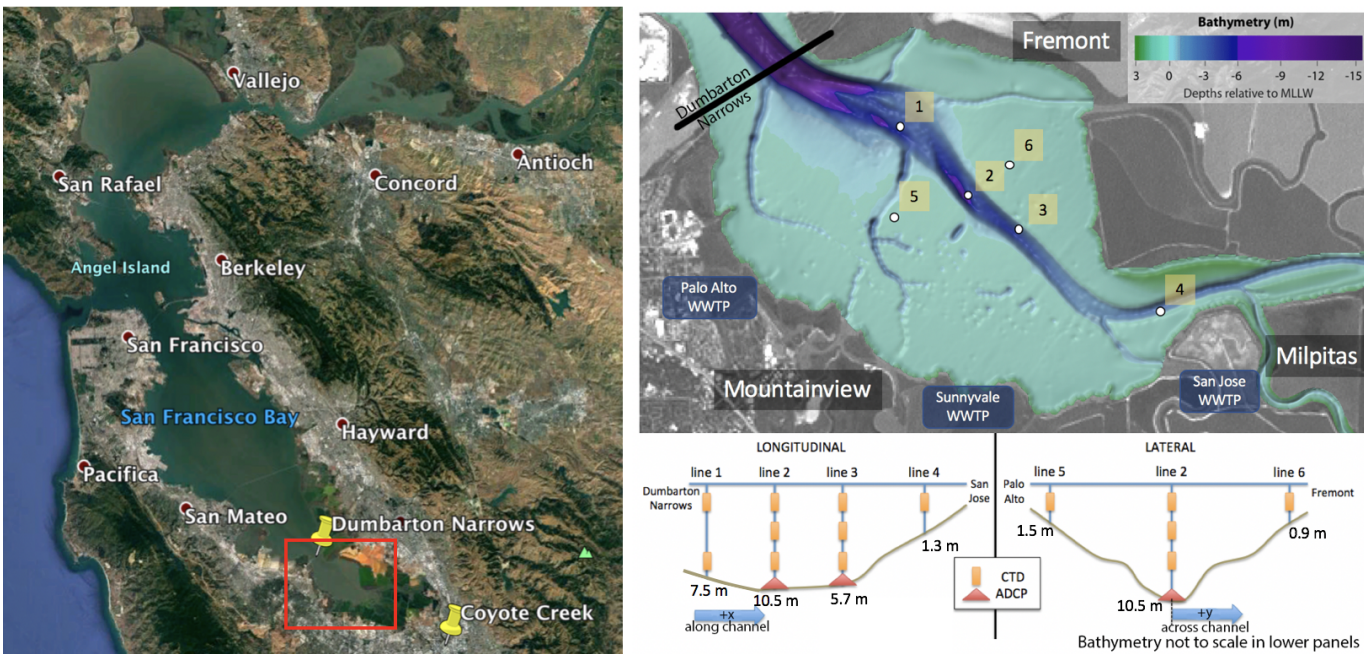

Figure 1: Bathymetry in Lower South San Francisco Bay consisting of a deeper, center channel in the Northwest to Southeast direction with broad, shallow shoals. White dots show where lines of CTD and ADCP's were placed for field deployment. Shades of purple correspond to $-15 \mathrm{~m}$ MLLW, dark blue -6 m MLLW, light blue $0 \mathrm{~m}$ MLLW, and green $3 \mathrm{~m}$ MLLW. Positive $x$ is defined in the southeast direction. Positive $y$ is defined in the northeast direction. Line 2 is centrally located and lies at $y=0$. See more details on mooring water depths in Table 1. Bathymetry from [Foxgrover et al., 2007]

Francisco Bay, Lower South San Francisco Bay, which extends roughly $10 \mathrm{~km}$ landward from the Dumbarton Narrows to the head of the estuary in Coyote Creek. Figure 1 shows how the bathymetry consists of a central channel with broad shoals on either side extending to perimeter marshes that are connected to the Bay through tidal sloughs. Freshwater from rainfall is typically observed from November to April with little to no rainfall inputs from May to October.

Observations were collected in Lower South San Francisco Bay (Lower SSFB) in order to observe how stratification is created or destroyed in an estuary that is strongly coupled with marsh habitats around its perimeter. Lower South San Francisco Bay sits within the urbanized and densely populated San Francisco Bay Area, and most of the freshwater flow into Lower SSFB is from wastewater returns, which bring with them high nutrient concentrations. Risks to future ecosystem conditions, and the role that nutrients may play in limiting or facilitating a transition to eutrophic conditions, have motivated a reconsideration of the dynamics of stratification in Lower SSFB. Recent evidence of decreasing turbidity reinforces concerns about threshold-like transitions in the system, particularly if stratification were to increase in strength or duration under future climate forcing [Cloern et al., 2011; Schoellhamer, 2011]. The proximity of these shallow perimeter habitats to the central channel emphasizes the importance of both lateral and longitudinal gradients in velocity and salinity. The bathymetry of the embayment, and the structure of the perimeter habitats, means the embayment has a tidal excursion on the same order of magnitude as the length of the estuary so that the center of the estuary will experience an influence from the perimeter within each tidal cycle, as well as from the Dumbarton Narrows to the north, which serves as the "mouth" for this sub-estuary. 


\begin{tabular}{ccc} 
Line & \multicolumn{2}{c}{ Latitude/Longitude } \\
1 & 37.48775 & -122.08939 \\
2 & 37.47754 & -122.07643 \\
3 & 37.472 & -122.06679 \\
4 & 37.45979 & -122.03996 \\
5 & 37.47415 & -122.09045 \\
6 & 37.48185 & -122.06825
\end{tabular}

Average Depth Below Surface [m] Top CTD Middle CTD Bottom CTD 2.4

1.0

0.5

1.0

0.6
NAVD88 Water Depth

[m] [m]

$\begin{array}{ll}-6.52 & 7.50\end{array}$

$-9.48 \quad 10.46$

$-4.68 \quad 5.66$

$-0.35 \quad 1.33$

$-0.47 \quad 1.45$

$0.12 \quad 0.86$

Table 1: Mooring Detailed Locations and Water Depths. Each CTD measures depth below the water surface. Here we display the average depth that the CTDs measured throughout the deployment. The column labeled NAVD88 provides the referenced depths from a Lower South Bay bathymetry dataset collected by the San Francisco Estuary Institute (SFEI) available on their ERDDAP website. The water depth at each mooring is estimated by taking the difference of the MSL at Alameda ( $0.98 \mathrm{~m}$ from NOAA Tides and Currents) from the NAVD88 bathymetry.

\subsection{Equipment Deployed}

In order to measure salinity gradients in the longitudinal, lateral, and vertical directions, a mesh of nine Ruskin RBR XR-420 CTDs and two Seabird SBE-37's were placed in various positions in all three dimensions. Locations of the lines are shown in Figure 1. Lines 1, 2, 3, and 4 were placed in the channel. Lines 5 and 6 were placed in the shallows, lateral to line 2. Line 1 has two CTD's attached at the top and bottom of the water column. Lines 2 and 3 have a top, middle, and bottom CTD. Line 4 has one CTD located near the surface of the water column. Lines 5 and 6 each have a Seabird attached at the surface of the water column. The RBRs and Seabirds measured conductivity, pressure (depth), and temperature, and calculated salinity, at one minute intervals. The RBR XR420 CTDs (Seabird SBE 37s) have a temperature accuracy of $\pm 0.002^{\circ} C\left( \pm 0.002^{\circ} \mathrm{C}\right)$ and pressure accuracy of $0.05 \%(0.1 \%)$ [Ruskin; Seabird Scientific].

Two Teledyne RD Instruments (RDI) $1200 \mathrm{kHz}$ Workhorse Monitor Acoustic Doppler Current Profilers (ADCP) were deployed at locations 2 and 3, and were tethered to the CTD lines by a bottom cable. The moored ADCPs were programmed to measure over a 12 meter water column with a vertical resolution of 0.25 meters with the first bin located 0.81 meters from the sea floor. The ADCPs, like the RBRs and Seabirds, collect ensemble averages every minute.

\section{Overview of Conditions}

\subsection{Salinity and Stratification}

Line 2 is the central line containing a top, middle, bottom CTD along with a moored ADCP. The deployment was slightly northeast of the center of the channel placing it closer to the east shoal, but protected from ship and fishing traffic.

Figure 2 displays the salinity measured from the top, middle, and bottom CTDs. The depth-averaged longitudinal velocity data from ADCP measurements were used to determine the start and end of each flood and ebb tide along with diurnal tidal asymmetries shown by hatching. Hatched regions are larger flood-ebb tides when the diurnal inequality is significant. Gray shaded regions are flood tides and white shaded regions are ebb tides. The precipitation in millimeters is shown at the bottom of Figure 2. Precipitation data was collected and distributed online by the California Irrigation Management Information System (CIMIS) [California Department of Water Resources]. There is no variation in temperature in the water column, and there is minimal temperature variation over the 
Line 2 Salinity and Precipitation: January 27, 2017 - February 11, 2017

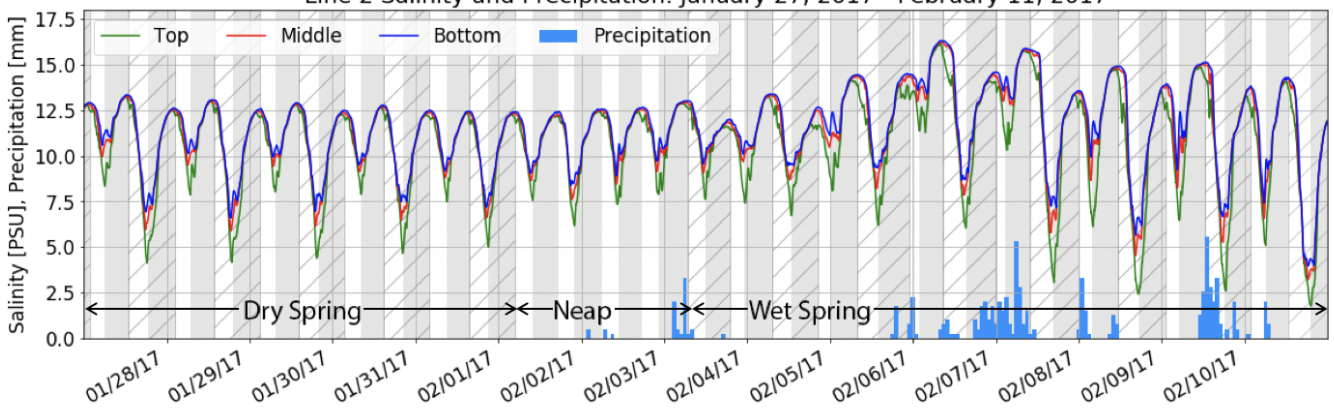

Figure 2: Salinity [PSU] and precipitation [mm] plot. Precipitation data from the California Irrigation Management Information System (CIMIS) station in Union City [California Department of Water Resources]. Note: Flood tides correspond to gray shading. Ebb tides correspond to white shading. Hatching refers to larger flood/ebb tides when there is a diurnal asymmetry. See Figure 6 for the longitudinal velocity time series clarifying shading and hatching periods.

time frame of the deployment. As a result, and in addition because of the smaller relative effect of temperature compared to salinity, density dependence on temperature is weaker than the dependence on salinity. The closest station to Lower South San Francisco Bay is located in Union City which is located about 13 kilometers from Line 2. There are three distinct conditions captured in the deployment. The first window, from January 27, 2017 to February 1, 2017 is a tidally energetic spring tide with distinct diurnal tidal asymmetry and limited precipitation. From February 1-3, 2017 is a neap tide with no tidal asymmetry and little to no precipitation. Finally, the last window from February 3-11, 2017 is another spring tide but with a series of significant precipitation events. Throughout the entire record, the typical tidal advective pattern is evident, with the water column freshening on ebbs and becoming more saline on floods. The range of salinity seen in a tidal cycle is roughly proportional to the magnitude of velocity in a particular tidal phase, which suggests that the dominant factor in the bulk variation of salinity is longitudinal tidal advection (Figure 2, 4a).

The vertical stratification of salinity (Figure 3 ) has more complex tidal variability. In Figure 3 we see stratification beginning to develop before the tidal transition from ebb to flood, which is consistent with SIPS [Simpson et al., 1990; Jay and Smith, 1990; Nepf and Geyer, 1996; Geyer et al., 2000; Scully and Geyer, 2012]. As a result, when the tide begins to turn at the end of the ebb tide, the water column is stratified, creating a vertical time lag in the reversal of the tidal flows. This results in strong water column shear during the transition from ebb to flood that causes the stratification to continue to intensify during this period. While this dynamic is, in general terms, consistent with dominance by longitudinal straining, the details of the intra-tidal variability of stratification show much more structure and variability than would be expected purely from SIPS. Specifically, stratification events associated with each slack tide are evident throughout most of the study period. At the end of each flood tide, the surface (top sensor) salinity drops, creating a short period of stratification (Figures 2 and 3). At the end of each ebb tide and into the beginning of the flood tide, there is another disruption in the typical longitudinally driven salinity pattern, this one is characterized by an increase in the salinities at all sensors, but with a time lag at the surface relative to the other sensors (Figure 2). The magnitude of this salinity feature ranges between 0.5 and 2 PSU. This salinity increase is too abrupt and tied to slack phasing to be longitudinal advection. 
There is no asymmetry in the amplitude of the two flood and ebb tides in a given day during the neap tide that occurs around February 1-3, 2017 (Figure 6), but the longitudinal salinity gradient remains roughly constant relative to the first spring tide (Figure 4). The result is that the minimum salinities within each tidal cycle are different during the neap (6-8 PSU) and the springs (large ebb: 4-6 PSU, small ebb: 8-10 PSU). Nonetheless, the variation of stratification around the slack tides remains qualitatively similar to the first spring tide period: there is still a sudden drop in the top salinity at the end of the flood tide and an increase in the top, middle, and bottom salinities at the end of each ebb tide. During the second spring tide (February 3-11, 2017), precipitation and runoff creates increased salinity variability, although many of the same features that were evident in the stratification during the early parts of the dataset persist. In particular during this period, the top salinity deviates even more from the middle and bottom salinities at the end of the flood tide and into the beginning of the ebb tide.
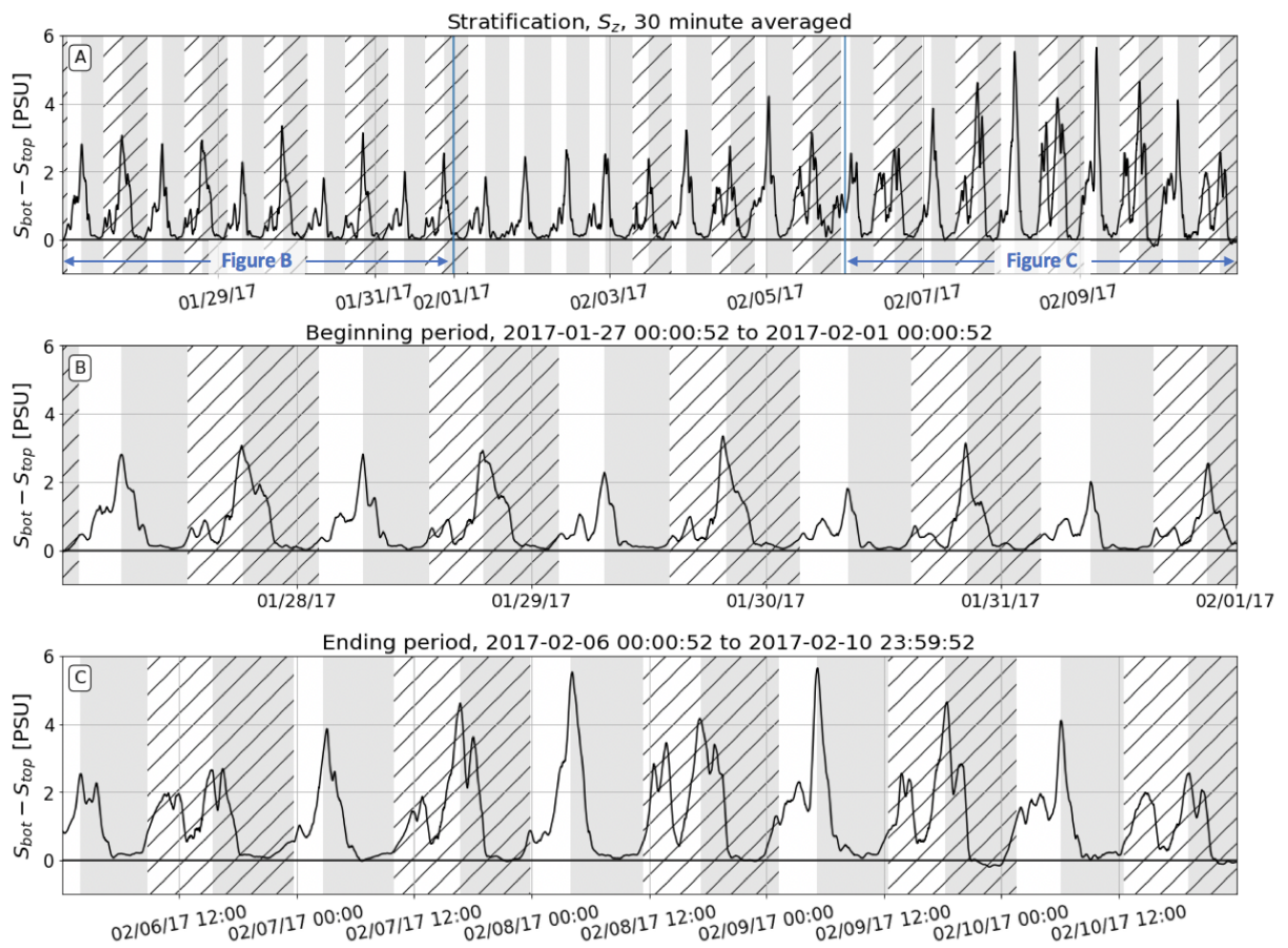

Figure 3: Stratification $\left(S_{z}\right)$ shown in units of PSU, is calculated by taking the difference in measured salinities in the bottom and top CTDs on line 2. Note: Flood tides correspond to gray shading. Ebb tides correspond to white shading. Hatching refers to larger flood/ebb tides when there is a diurnal asymmetry.

SIPS based on longitudinal straining predicts the largest stratification at the end of the ebb tide and well-mixed conditions at the end of the flood tide. In Figure 3 the general pattern of stratification shares many features with this basic pattern, with wellmixed conditions developing from mid to late flood, and stratification generally increasing through the ebb tides. The larger ebb tides tend to create stronger stratification events in the first weeks shown in Figure 3b, but this pattern is not as consistent in the latter part of the data set when there is higher buoyancy input to the system (Figure 3c). During most flood tides there is a total break down of the stratification that was developed over the ebb tide. There are a few instances in Figure $3 c$ in which stratification is not eliminated dur- 
ing the flood tide creating stratified water columns that persists over one or two days (i.e. February 6, 18:00 and February 8, 9:00). Further, the development of stratification initiates slightly earlier than traditional SIPS would predict, with stable conditions beginning to develop before the turn of the tide. Finally, we note that, in general terms, flood-ebb asymmetry of turbulent mixing accelerates destratification early in the flood tide leading to, on average, less stratified flood tides than ebb tides consistent with what's been seen in estuarine literature such as Scully and Geyer, 2012, Geyer et al., 2000, Nepf and Geyer, 1996. Additionally, the influence of turbulent mixing is evident during the peak ebb tides, particularly during the wet period at the end of the record (Figure 3c), where stratification decreases during the mid-ebb, indicating that turbulent mixing is able to overcome the stabilizing influence of longitudinal straining.

In contrast to traditional SIPS dynamics, during both the dry spring tide and the wet spring tide, stratification begins to develop at the end of the flood tide and continues to grow over the ebb tide. We can also see that the destruction of stratification over the flood tide is not gradual like we would expect if it were longitudinally-driven. The destratification process occurs in two or three separate instances at the beginning of the flood tide and then the water column is completely destratified by mid-flood. This complexity associated with the turning of the tide from ebb to flood and from flood to ebb suggests higher-dimensional processes than is described by longitudinal SIPS. In order to determine what is driving these features, we must break down how longitudinal advection, longitudinal straining, lateral advection, and lateral straining contribute on the tidal timescale.

\subsection{Salinity Gradients}

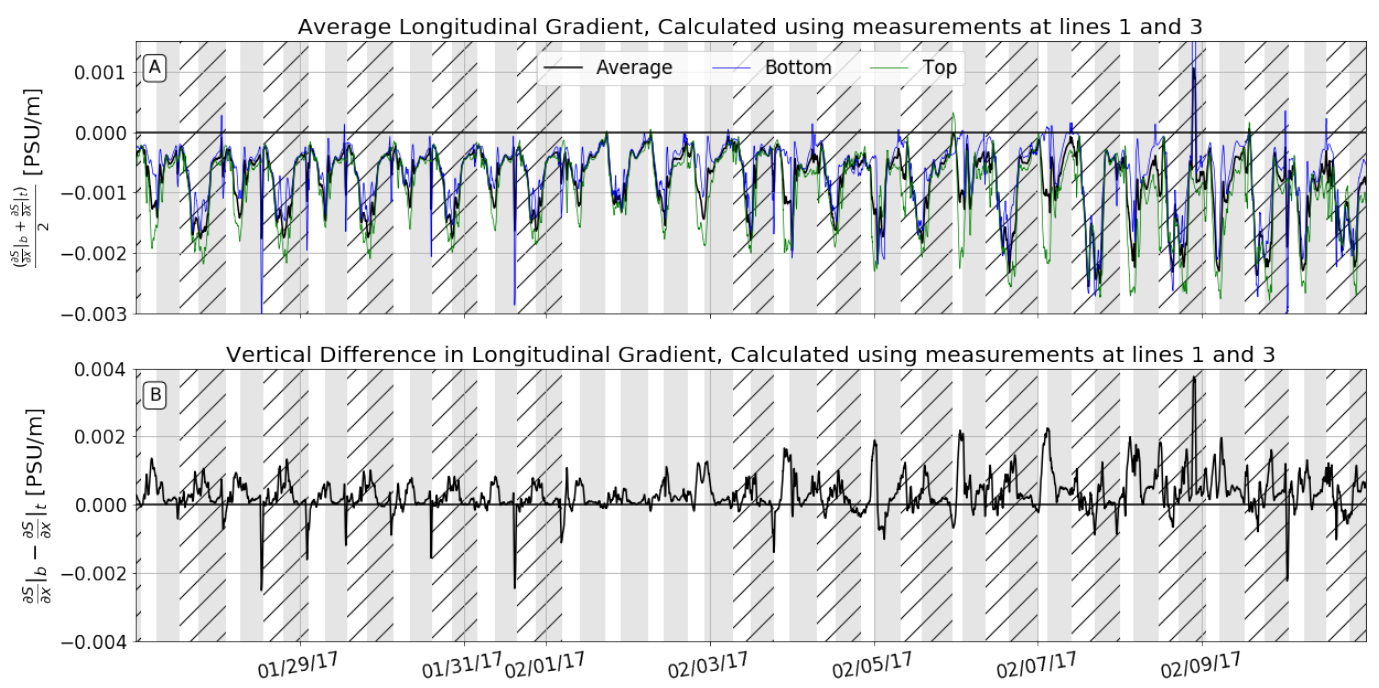

Figure 4: Longitudinal Salinity Gradient [PSU/m] calculated using instantaneous salinity measurements at lines 1 and 3. Top plot shows the average longitudinal salinity gradient and the bottom plot shows the vertical difference. Note: Flood tides correspond to gray shading. Ebb tides correspond to white shading. Hatching refers to larger flood/ebb tides when there is a diurnal asymmetry.

To define the longitudinal salinity gradient at our central station (line 2), differences between lines 1 and 3 were used. Both lines 1 and 3 also have a top and bottom CTD which allows for comparing longitudinal salinity gradients at the top and at the bottom. $x$ is defined as positive up-estuary (to the southeast), therefore, the longitudinal salinity gradient, $\frac{\partial S}{\partial x}$, is expected to be negative. Figure 4a shows that, although the longitudinal 
salinity gradient is consistently negative throughout the tidal cycle, it becomes more negative during the ebb tide. This tidal variation of $\frac{\partial S}{\partial x}$ indicates the presence of a non-linear salinity gradient, with stronger gradients that develop near the perimeter being advected into our observation site during the ebb tides. The largest magnitude of the longitudinal stratification gradient occurs at the end of the ebb tide and decreases through the flood tide as the influence of the Dumbarton Narrows is advected into the study site (Figure $4 \mathrm{~b}$ ). During the neap tide, the observed longitudinal gradient in stratification reaches zero at the end of the flood tide. The influence of a zero longitudinal stratification gradient shows up in the longitudinal advection term in the dynamic stratification equation indicating the advection of an unstratified water mass from north of the Dumbarton Narrows to the location of line 2. Since the longitudinal stratification gradient decreases in magnitude on flood tides, we hypothesize that higher velocities through the constriction at the Narrows creates turbulent mixing and destratifies the water column that is inputted into the estuary from the mouth. The unstratified water at the Narrows is then advected upstream on the flood tides.

There are a few unexpected signals in the tidal signal of the longitudinal gradient at the end of the ebb tide and at the end of the flood tide. At the end of each ebb tide there is a decrease in the magnitude of the longitudinal gradient that persists for only an hour or two and appears to be due to a pulse of saline waters evident at the middle and bottom up-estuary CTDs that is not shown in the down-estuary CTDs causing the salinities in the two locations to converge at the end of the ebb tide. This could be explained by lateral circulation bringing saltier water to the bottom of the up-estuary location at the end of the ebb or the longitudinal advection of a salt wedge. At the end of the flood tide, we see a large, sudden increase in the magnitude of the average longitudinal gradient. This is due to a pulse of freshwater at the up-estuary station, creating the increase in the longitudinal salinity gradient.

The vertical variation of longitudinal stratification $\left(\frac{\partial^{2} S}{\partial z \partial x}\right.$, Figure $\left.4 \mathrm{~b}\right)$ tends to be positive, indicating stronger stratification up-estuary. The advection of this gradient is responsible, in part, for the observed tidal variation of stratification, and is strongly shaped by specific features of the embayment. During the ebb tide, $\frac{\partial S}{\partial z}$ increases as a stratified water mass from up-estuary is advected into our observation site (Figure 3). On floods, mixing at the Dumbarton Narrows likely homogenizes the water column, so that during the flood tide, increasingly destratified conditions are advected into the study site. This dynamic is intensified during the last half of the observation period, as buoyancy input (precipitation and runoff) intensifies the density gradients, but not sufficient to overcome the flood tide mixing.

The lateral salinity gradient was calculated using salinity measurements at line 2 and line 6 . This pattern at line 5 was similar to that at line 6 , but consistently weaker. Due to the timing of the deployment with the water level, we were unable to get line 5 closer to the perimeter. If we were able to get line 5 closer to the western perimeter, we would have a stronger lateral salinity gradient measurement between lines 2 and 5. For clarity, we only use the lateral salinity gradient that is measured between lines 2 and 6 . Line 6 only has one top salinity measurement, so it was necessary to assume there is no stratification in the shoals [Scully and Friedrichs, 2007]. Figure 5 shows the measured lateral salinity gradient, $\frac{\partial S}{\partial y}$, using only the top salinity measurements at lines 2 and 6 (dashed) and then by using a depth-averaged salinity at line 2 and the salinity measurement at line 6 (solid line). The average lateral gradient is negative most of the time, indicating that the shoals are persistently fresher than the channel. However, at the end of many ebb tides, the gradient switches signs, meaning the shoals are more saline than the channel at these times. This tidal variability of the lateral salinity gradient is consistent with differential tidal advection, where $\frac{\partial S}{\partial t} \approx-U \frac{\partial S}{\partial x}$. Differential tidal advection tells us that the tidal reach in the channel is greater than the tidal reach in the shoal. Therefore, over the ebb tide, both the channel and the shoals are getting fresher, but the channel is getting fresher at 


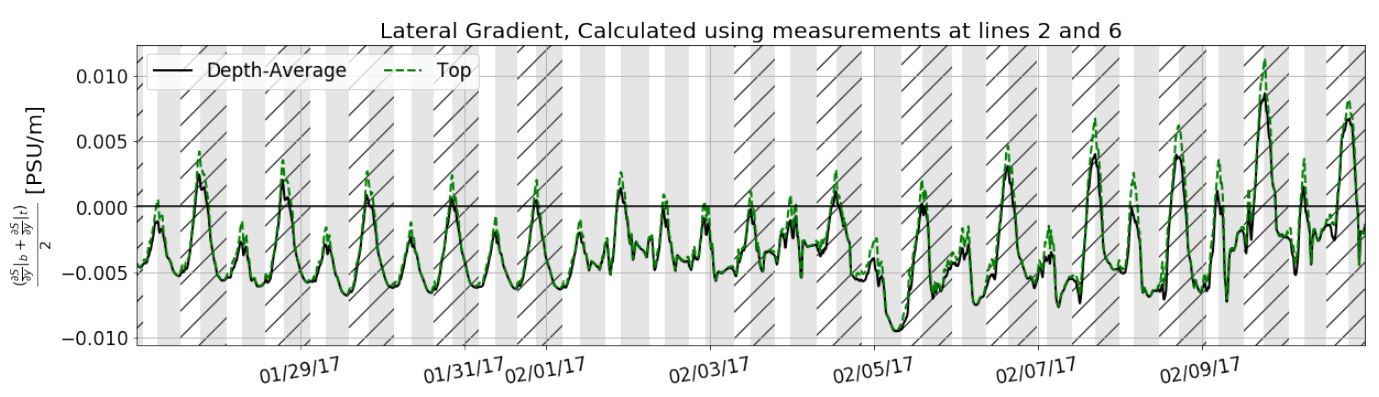

Figure 5: The lateral salinity gradient [PSU/m] was calculated using instantaneous salinity measurements at lines 2 and 6 . The average lateral salinity gradient was calculated using the top and bottom salinity measurements at line 2 and the top salinity measurement at line 6 . Due to limitations in field measurements it is assumed that in the shoal is well-mixed at line 6 allowing us to use the top salinity measurement for the entire water column. The top lateral salinity gradient (dashed) is calculated by using only the measurements at the top of lines 2 and 6 which reveals a reversal sign by the end of the ebb tide meaning the shoal is saltier than the channel through differential advection.

a faster rate than the shoals. As we can see in Figure 5, differential advection creates a reverse gradient by the end of the ebb tide meaning the channel is fresher than the shoal.

\subsection{Velocity}

Velocity measurements were taken throughout the water column in $25 \mathrm{~cm}$ bins using a Teledyne ADCP at line 2. The velocity measurements were then rotated to fit the along-channel, longitudinal direction as $u$ and the across-channel, lateral direction as $v$. The along-channel or longitudinal orientation was determined by fitting a best fit line to the scatter of measured east velocity and measured north velocity. The depth-averaged longitudinal velocity, $\bar{u}$, was then used to define the start and end of each flood and ebb tide shown in shading in each plot. The coordinate system was defined as flood in the positive $x$-direction and ebb in the negative $x$-direction; the $y$-direction is positive to the northeast. In order to calculate water column averaged vertical shear in velocity, the measured velocities in the top 2 meters from the water surface were averaged to get $u_{t o p}$ and the bottom 2 meters of measured velocity were averaged to get $u_{\text {bottom }}$, and the longitudinal shear velocity was calculated as $u_{\text {bottom }}-u_{\text {top }}$.

Figure 6a shows the top and bottom longitudinal velocities. The tidal asymmetries are clear during the spring tides, and the larger of the diurnal tides are marked with hatching. The start and end of each tide is defined by the zero crossing of the depth-averaged longitudinal velocity. The depth-averaged shear, $u_{b}-u_{t}$, is expected to be positive on ebb tides and negative on flood tides. However, Figure $6 \mathrm{~b}$ shows that the difference between the bottom and top longitudinal velocities at a given time is mostly positive for both tides. The small, slightly positive shear in the flood is due to the longitudinal salinity gradient and well-mixed conditions producing a fairly uniform velocity profile where the magnitude of the top velocity is marginally smaller than the bottom velocity.

A second mechanism that alters the expected tidal variability of water column-averaged shear is the vertical lag in the reversal of the tides during the transition from ebb to flood. In the transition from flood to ebb, the water column reverses direction together, with very little phase lag. In the transition from ebb to flood, however, the near-bed velocities reverse as much as an hour or two before the upper water column, leading to periods of inverted shear and, as a result, straining in the direction favoring stratification. Similarly, observations in the York River estuary showed that the ebb in the channel was consistently longer than the ebb in the shoal because there was more friction in the shoal which re- 

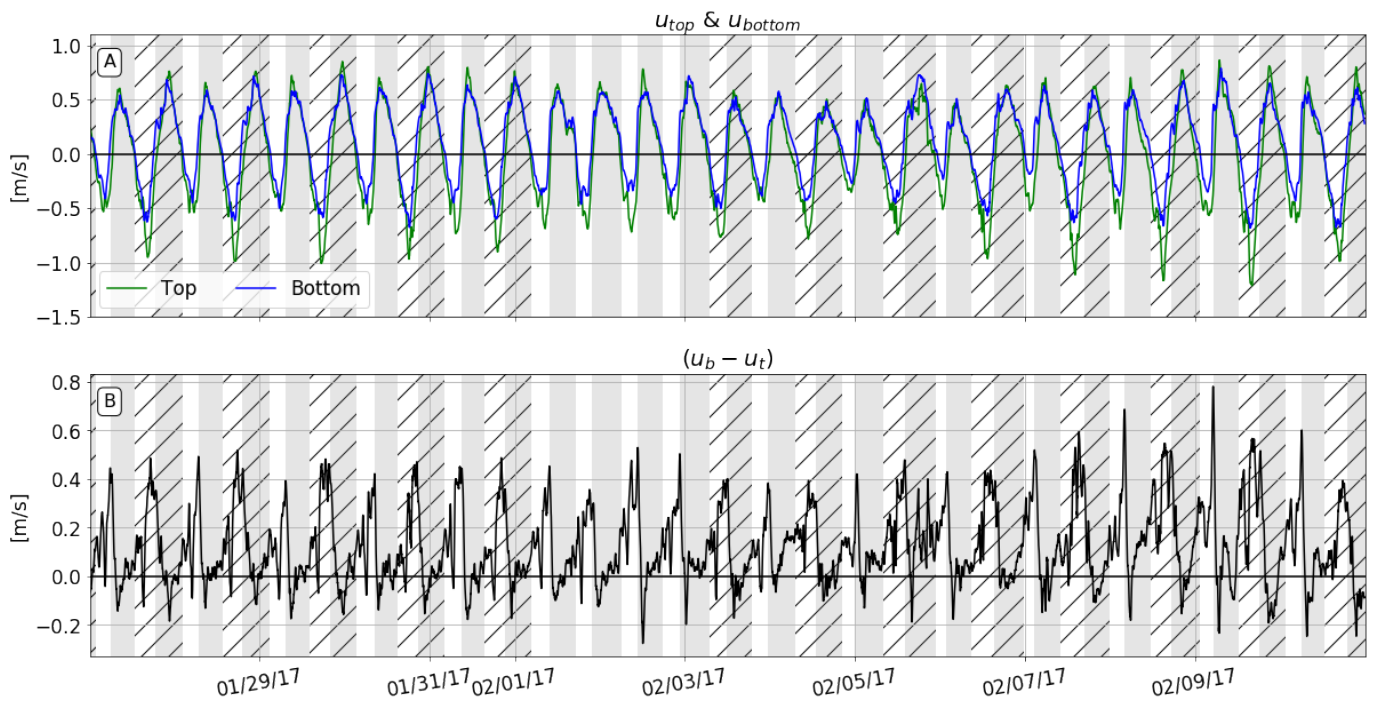

Figure 6: Top and bottom longitudinal velocities $[\mathrm{m} / \mathrm{s}]$ were calculated by averaging the longitudinal velocities in the top $2 \mathrm{~m}$ and the bottom $2 \mathrm{~m}$ of the water column. Tidal asymmetries were defined visually by the amplitude of the top longitudinal velocity. (A) shows the time variation of top and bottom longitudinal velocity and (B) shows the shear. Note: Flood tides correspond to gray shading. Ebb tides correspond to white shading. Hatching refers to larger flood/ebb tides when there is a diurnal asymmetry.

versed the tide quicker than in the channel where the momentum from the previous tide could continue longer [Scully and Friedrichs, 2007].

Lateral flow in a shoal-channel estuary results from barotropic (tidal) forcing, wind forcing, or baroclinic (density) forcing. Tidal variability will occur in both the barotropic (directly) and baroclinic (through differential advection as discussed above) components and we will focus on those forcing mechanisms here. The approach we took to defining the coordinate axis for the barotropic tides leaves some lateral flow due to variation in the alignment of the bathymetry with our coordinate axes. As shown in Figure 1, line 2 is located on the edge of a local deeper part of the channel which causes the primary axis to be at a sharper angle from the larger channel. We highlight that since line 2 lies on the northeast side of the deepest part of the channel, positive lateral velocities are flows from the channel towards the shoals and negative lateral velocities are flows from the shoals towards the channel.

The reversing sign of the lateral density gradient in Figure 5b suggests that the exchange between the channel and shoal should itself reverse signs tidally, with a positive near surface flow (and negative near-bottom flow) during one slack tide and the reverse during the other. Figure 7 a confirms that there are many instances where the lateral velocity is directed in opposite directions at the top and the bottom, between 10 and $20 \mathrm{~cm} / \mathrm{s}$. During mid-flood the bottom lateral velocity is negative, or in the southwest direction, and the top lateral velocity is smaller in magnitude, but in the positive, or northeast direction. We hypothesize that this shear represents the influence of baroclinic pressure gradients. Then at the end of each ebb tide, there is a short, but large magnitude lateral shearing event as shown by abrupt, positive peaks in Figure $7 \mathrm{~b}$. 

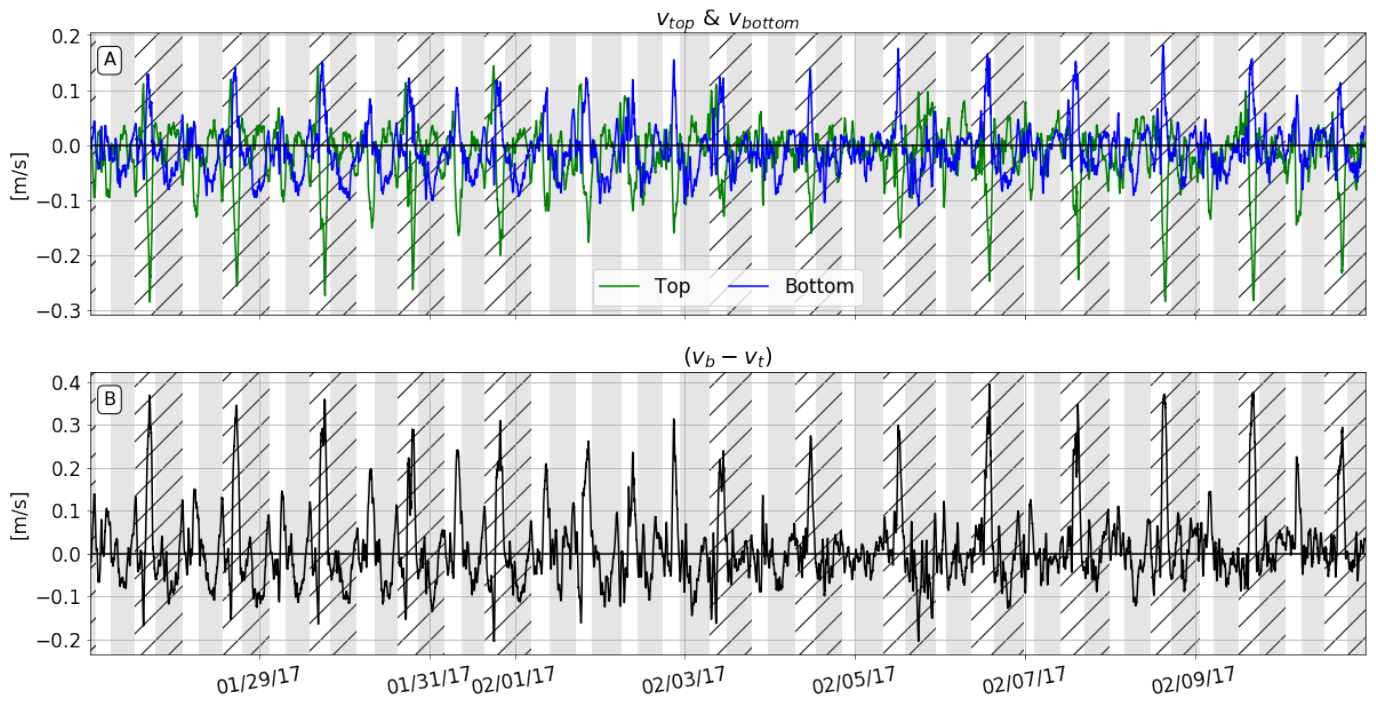

Figure 7: Top and bottom lateral velocities $[\mathrm{m} / \mathrm{s}]$ were calculated by averaging the lateral velocities in the top $2 \mathrm{~m}$ and the bottom $2 \mathrm{~m}$ of the water column. (A) shows the time variation of top and bottom lateral velocity and (B) shows the shear. Large shear events consistently occur at the end of the ebb tide in both the spring and neap. Persistent lateral exchange, but small magnitude, occurs over the flood tide. Note: Flood tides correspond to gray shading. Ebb tides correspond to white shading. Hatching refers to larger flood/ebb tides when there is a diurnal asymmetry.

\section{Analysis}

We now turn to an analysis of the mechanisms responsible for the creation and destruction of stratification. The stratification, $S_{z}=S_{\text {bottom }}-S_{\text {top }}$, at line 2 shows variability at tidal and spring-neap timescales, as well as in response to precipitation events (Figure 8). The framework we will use to evaluate changes in stratification starts with the standard Reynolds-averaged, advection-diffusion equation with constant eddy diffusivity for salt in the estuary:

$$
\frac{\partial S}{\partial t}+u \frac{\partial S}{\partial x}+v \frac{\partial S}{\partial y}+w \frac{\partial S}{\partial z}=K\left(\frac{\partial^{2} S}{\partial x^{2}}+\frac{\partial^{2} S}{\partial y^{2}}+\frac{\partial^{2} S}{\partial z^{2}}\right)
$$

Taking the vertical derivative of this equation and rearranging, we arrive at:

$$
\frac{\partial}{\partial t} \frac{\partial S}{\partial z}+\frac{\partial u}{\partial z} \frac{\partial S}{\partial x}+u \frac{\partial^{2} S}{\partial z \partial x}+\frac{\partial v}{\partial z} \frac{\partial S}{\partial y}+v \frac{\partial^{2} S}{\partial z \partial y}+\frac{\partial w}{\partial z} \frac{\partial S}{\partial z}+w \frac{\partial^{2} S}{\partial z^{2}}=\frac{\partial}{\partial z} K\left(\frac{\partial^{2} S}{\partial x^{2}}+\frac{\partial^{2} S}{\partial y^{2}}+\frac{\partial^{2} S}{\partial z^{2}}\right)
$$

Assuming turbulent mixing in the horizontal dimensions is small compared to the vertical dimension (i.e., the depth is much smaller than the lengthscales associated with horizontal gradients) and that vertical advection can be neglected, equation (8) is reduced to unsteadiness, the next four terms on the left hand side and the last term on the right. Moving all of these terms to the right hand side makes for a consistent sign convention (positive menas creating stratification, negative means destratifying). These five terms are:

1. Longitudinal straining, $-\frac{\partial u}{\partial z} \frac{\partial S}{\partial x}$

2. Longitudinal advection, $-u \frac{\partial^{2} S}{\partial z \partial x}$

3. Lateral straining, $-\frac{\partial v}{\partial z} \frac{\partial S}{\partial y}$

4. Lateral advection, $-v \frac{\partial^{2} S}{\partial z \partial y}$

5. Mixing, $K \frac{\partial^{3} S}{\partial z^{3}}$ 


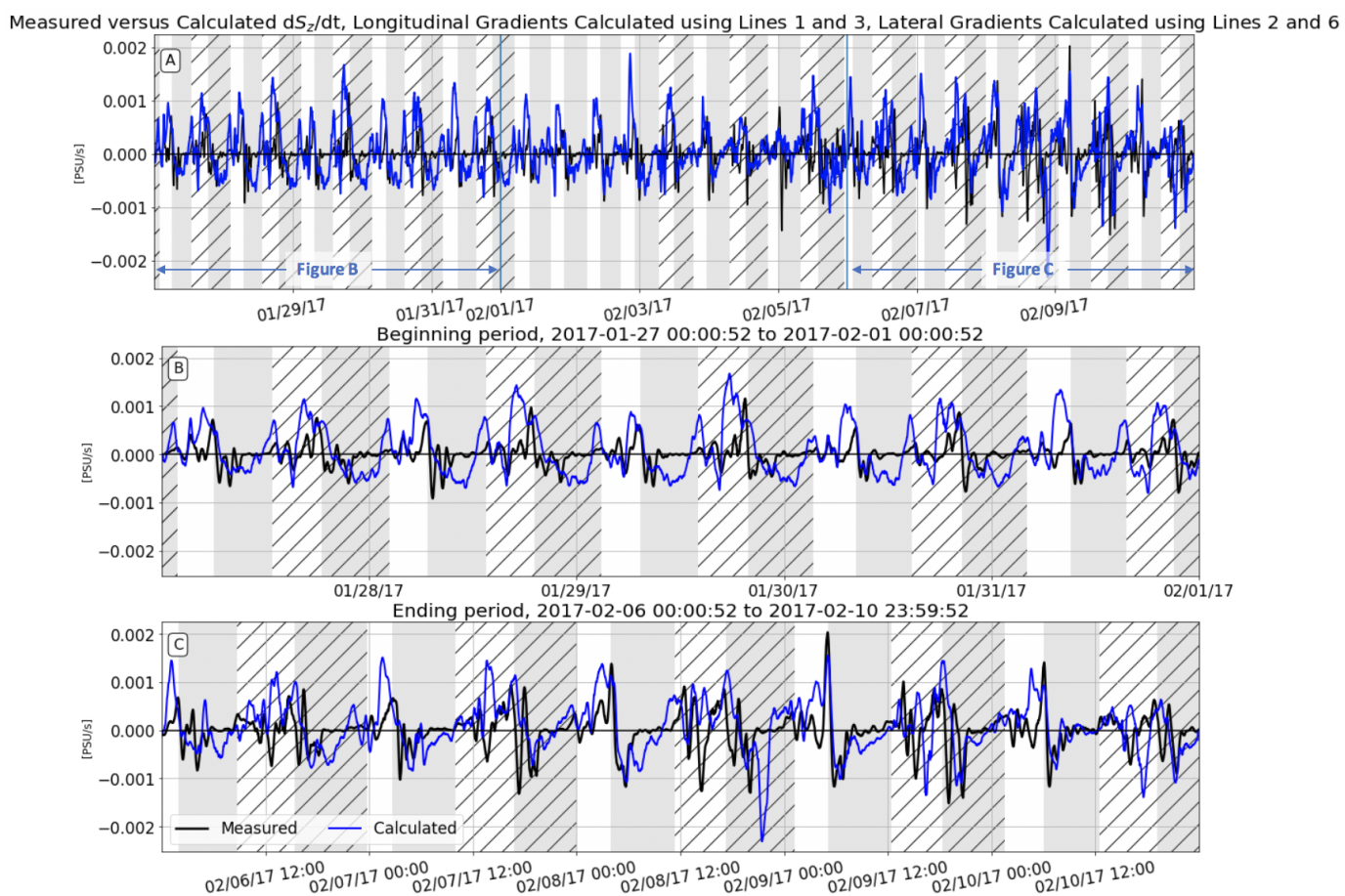

Figure 8: The measured rate of change of stratification (black), $\frac{\partial S_{z}}{\partial t}\left[\frac{P S U}{s}\right]$, was calculated by taking the time derivative of the bottom-top salinity difference at line 2 and with a rolling-average window of 30 minutes. The calculated rate of stratification (blue), was calculated by taking the sum of observed values of longitudinal straining, longitudinal advection, lateral straining, and lateral advection. (A) Entire time series, (B) First, dry spring tide, (C) Second, wet spring tide. Note: Flood tides correspond to gray shading. Ebb tides correspond to white shading. Hatching refers to larger flood/ebb tides when there is a diurnal asymmetry.

From the data, we can directly calculate the time variability of the stratification (first term in equation 8) using a central differencing scheme to approximate the time derivative of the difference between top and bottom sensors at line 2, the vertical stratification, as plotted in Figure 8a). In this figure, it is evident that stratification variations are strongest (largest magnitude) at the end of the ebb tide and the beginning of the flood tide. Generally, we see negative changes in stratification (destratification) in two distinct events at the beginning of the flood tide. These two peaks cause the stair-step change in stratification that was seen in Figure 3. Generally, the rates of change of stratification were greater during the period with precipitation (Figure 8c) than during dry period (Figure 8b), but the qualitative patterns are similar: the creation of stratification is most prominent at the end of the ebb tide, and the destruction of that stratification in two or three peaks at the beginning of the flood tide.

To evaluate the forcing mechanism responsible for changes in stratification, we approximate the vertical derivatives using a layered model and aggregate the data into nearbottom and near-top layers. For salinity, the bottom and top sensors are assumed to represent layer averages; for the velocity data, we bin-average over the bottom or top 2 meters to define each layer. With subscripts $b$ and $t$ denoting the bottom and top layers, respectively, we approximate each of the terms as:

1. Longitudinal straining, $-\left(u_{b}-u_{t}\right)\left(\frac{\left.\frac{\partial S}{\partial x}\right|_{b}+\left.\frac{\partial S}{\partial x}\right|_{t}}{2}\right)$ 
2. Longitudinal advection, $-\frac{u_{b}+u_{t}}{2}\left(\left.\frac{\partial S}{\partial x}\right|_{b}-\left.\frac{\partial S}{\partial x}\right|_{t}\right)$

3. Lateral straining, $-\left(v_{b}-v_{t}\right)\left(\frac{\left.\frac{\partial S}{\partial y}\right|_{b}+\left.\frac{\partial S}{\partial y}\right|_{t}}{2}\right)$

4. Lateral advection, $-\frac{v_{b}+v_{t}}{2}\left(\left.\frac{\partial S}{\partial y}\right|_{b}-\left.\frac{\partial S}{\partial y}\right|_{t}\right)$

\subsection{Longitudinal Straining}

Longitudinal straining creates and destroys stratification through the straining of the longitudinal salinity gradient by a vertical velocity gradient. Tidally, this terms is expected to be positive on ebb and negative on flood, with peak values associated with peak longitudinal shear. Variations from this would be due to tidal changes in the longitudinal salinity gradient, or asymmetries in the vertical shear, which would follow from the feedback through stratification and resulting decreases in mixing.
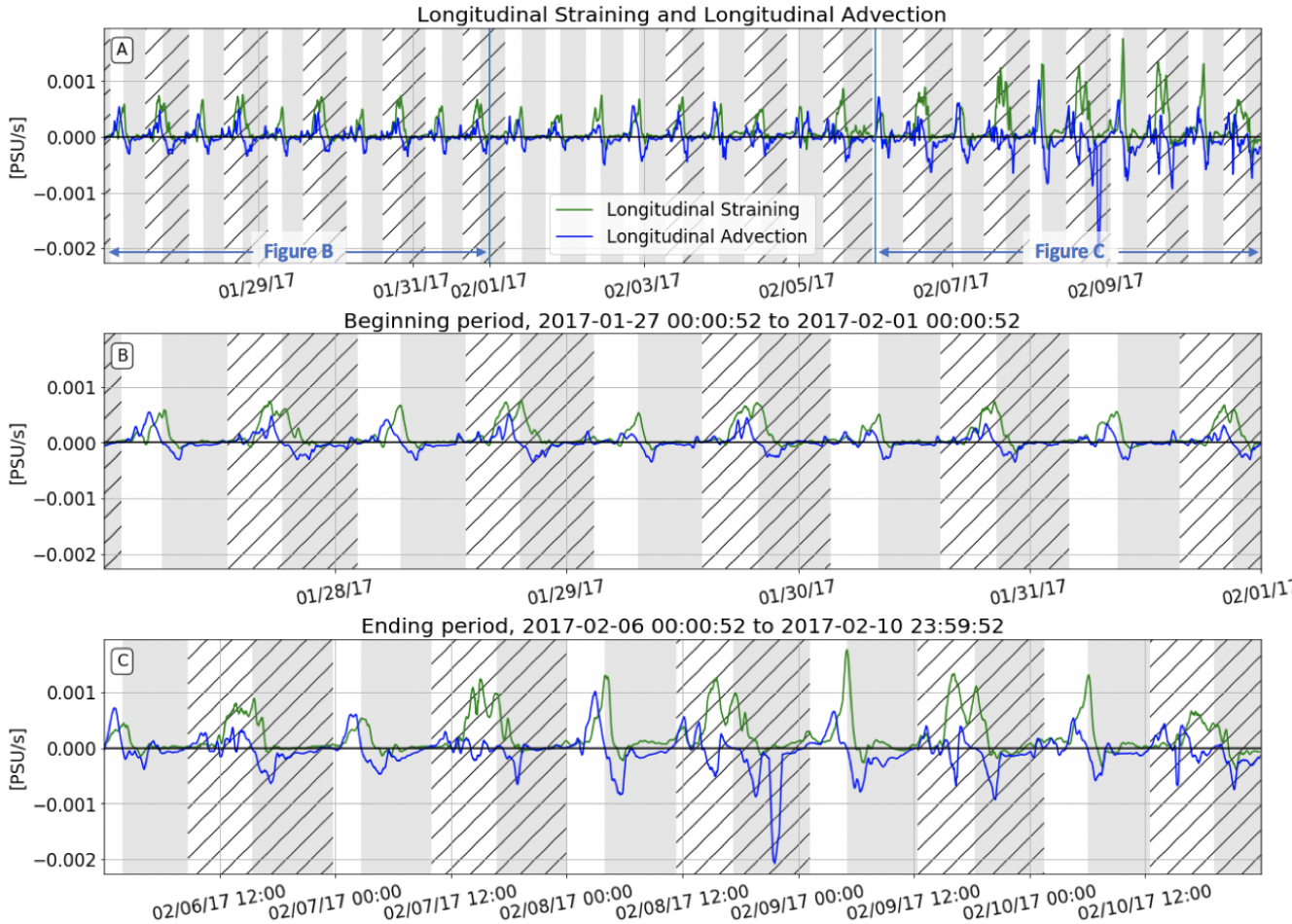

Figure 9: Longitudinal Straining and Longitudinal Advection in [PSU/s]. Longitudinal salinity gradients were calculated using lines 1 and 3. (A) Entire time series, (B) First, dry spring tide, (C) Second, wet spring tide. Note: Flood tides correspond to gray shading. Ebb tides correspond to white shading. Hatching refers to larger flood/ebb tides when there is a diurnal asymmetry.

As shown in Figure 9, the longitudinal straining term is generally positive, indicating a source of stratification, with some negative values (destratification) during the flood tides. This ebb-flood asymmetry in the influence of straining is due to differences in the shear $\left(\frac{\partial u}{\partial z}\right)$, not the longitudinal salinity gradient (Figures $4 \& 6$ ), with the ebbs considerably more sheared than the floods. A notable feature in the longitudinal straining term is the large positive peak at the transition from ebb to flood, which is due to the vertical phase lag in the reversal of the tide [Stacey et al., 2001].

In the last portion of the data set, when there is an increase in buoyancy via rainfall (Figure 9c), longitudinal straining continues to have the same ebb-flood pattern and asymmetry, but with a larger magnitude. The highest rate of stratification occurs from mid to 
late ebb, and there is a small creation of stratification at the transition into the flood tide, but the contribution of this term is small through the remainder of the flood tide.

\subsection{Longitudinal Advection}

The longitudinal advection term is the translation of salinity gradients in the $x$ direction. This term is calculated by taking the product of the depth-averaged longitudinal velocity and the second order salinity gradient in the $x$ - and $z$-directions. Positive (negative) values of this term means the upstream (downstream) stratification is greater than the local or downstream (upstream) stratification. If the portions of the estuary adjacent to perimeter habitats are more stratified than the "mouth" at the Dumbarton narrows, we would expect this term to be negative on the flood tide and positive on the ebb tide.

The blue line in Figure 9a shows a persistent translation of stratification to our central site on ebbs due to longitudinal advection and the reverse on floods due to longitudinal advection. This tidal pattern is consistent with the expectation that the water column is well-mixed at the Dumbarton Narrows and more stratified near the perimeter. Positive values of longitudinal advection during the ebb tide translate to more stratified water near the perimeter advecting to the center of the estuary and reaching a maximum at the end of the ebb. During the flood tide, this term is negative as it translates the well-mixed waters from the mouth to the center of the estuary. This result highlights the importance of localized mixing (at a specific location like the Narrows) in the stratification dynamics of adjacent embayments. When there is an increase in buoyant input, the magnitude of longitudinal advection is greater, which is likely due to the fact that the stratification difference between the mouth of the estuary and near the perimeter of the estuary is increased when there is more freshwater input (Figure 9c).

\subsection{Lateral Straining}

Lateral straining is the creation or destruction of stratification due to the lateral straining of the lateral density gradients. The lateral salinity gradient is almost always negative (Figure 5a) as the water in the shoals are fresher than the water in the channel except at the end of the ebb tide when differential advection causes the channel to be fresher than the shoals. While the lateral circulation is expected to be driven by the lateral density gradient, we use the observed bottom-top velocity difference $\left(v_{b}-v_{t}\right.$, Figure $7 b)$ to determine a negative $v_{b}-v_{t}$ persists through much of the flood tides, but this shear reverses briefly at the end of each ebb tide, coincident with the reversal of the lateral density gradient. It is difficult to see clear signals of lateral exchange from the lateral velocity and lateral salinity observations as even when the lateral salinity gradient remains negative during the small ebb tides, we still observe increases in salinity. This could be due to the location that the shoal salinity is measured.

As a result of the correlation between lateral shear and lateral density gradients, the contribution of lateral straining to stratification in the channel is expected to be positive (stratifying); since density driven flow can only be stratifying, any negative contributions to stratification indicate that the forcing of the lateral circulation must come from other mechanisms such as bathymetric effects on the tides (channel curvature or the effects of broad shoals and storage), Coriolis, and wind. Reinforcing the density-driven mechanism for the lateral circulation, there is a recurring positive peak at the end of the flood tide, when the lateral density gradient and circulation are strongest. This peak is created by the interaction of differential advection building up the lateral density gradient throughout the flood tide until the reduction in turbulent mixing at the end of the flood tide allows lateral exchange flow to develop.

In the first couple of tidal cycles in Figure 10b, during the ebb tide, the lateral straining term is variable, with sign changing between positive and negative throughout the ebb. 

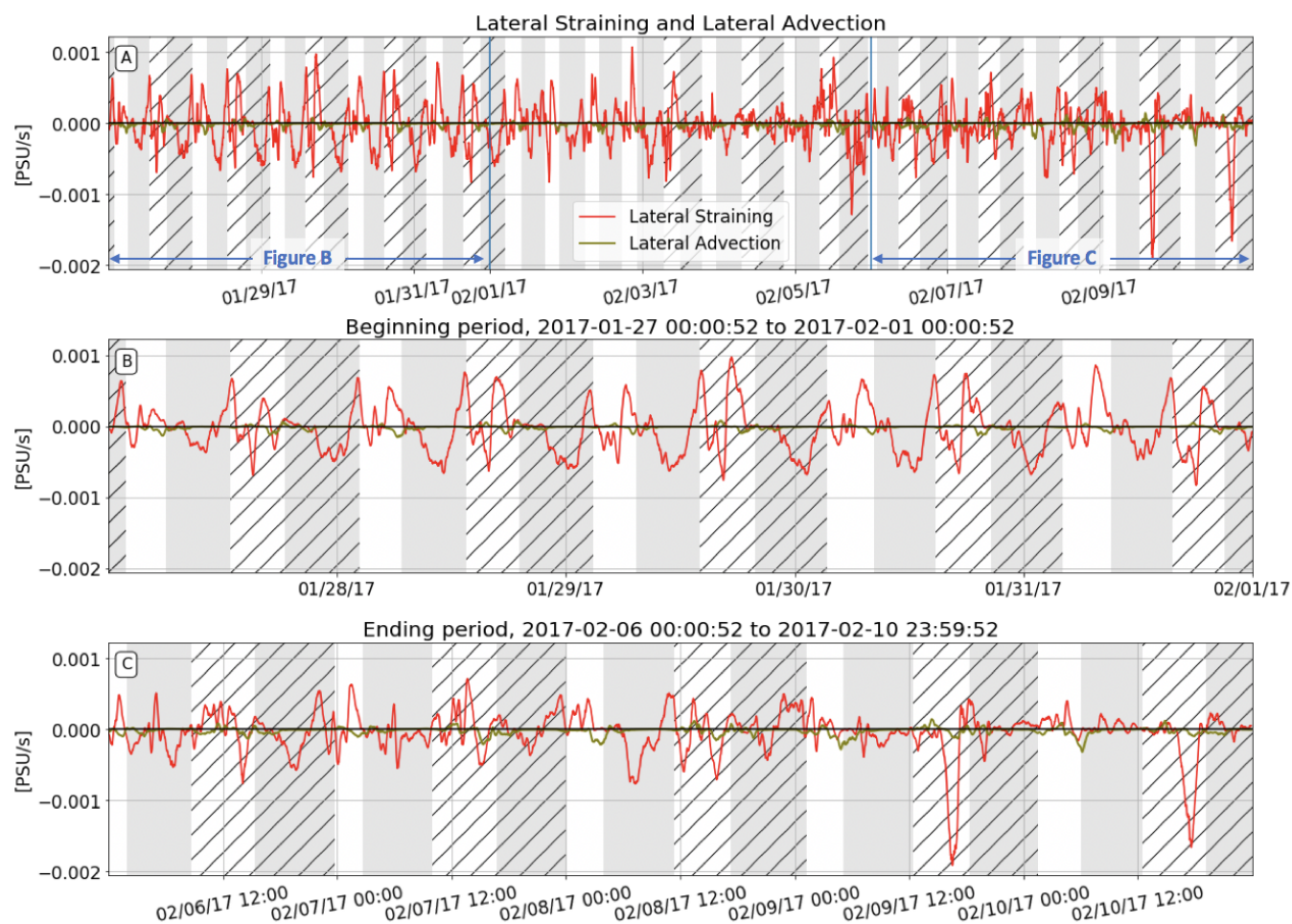

Figure 10: Lateral Straining and Lateral Advection in [PSU/s]. Lateral salinity gradients were calculated using lines 2 and 6. (A) Entire time series, (B) First, dry spring tide, (C) Second, wet spring tide. Note: Flood tides correspond to gray shading. Ebb tides correspond to white shading. Hatching refers to larger flood/ebb tides when there is a diurnal asymmetry.

Although highly variable, this pattern is consistent over the ebb tides in the dry spring. During the flood tides (gray shading), the lateral straining term is negative mid-flood tide, then increases to a maximum positive value by the end of the flood tide. The ebb-to-flood transition does not show a significant contribution from lateral straining, which is consistent with the fact that the lateral density gradients are quite small at this time.

At each mid-flood tide, lateral straining contributes negatively to stratification, but during a period when the water column is already well-mixed entirely (Figure 3). In order for lateral straining to contribute to destratification, the orientation of the straining must be the opposite of expected under only density forcing. We are seeing here the lateral equivalent to overstraining [Nepf and Geyer, 1996] and therefore lateral straining is contributing to turbulent mixing during the flood tides. To be clear, we hypothesize that this is really just a directional shear that is created by the interaction of the tides with the shoal-channel transition, and not a new lateral mechanism. However, it indicates that estimates of straining based purely on longitudinal gradients and shear would underestimate the magnitude of overstraining.

\subsection{Lateral Advection}

The final term that can be directly calculated is small throughout the tidal cycle due to the fact that the depth-averaged lateral velocity is small. Deviations from zero occur during periods of time when the depth-averaged velocity does not align with the primary tidal axis, which was used to define the rotation of the coordinate axis. The only period of time when the term contributes is near the end of the ebb tide, when barotropic forcing 

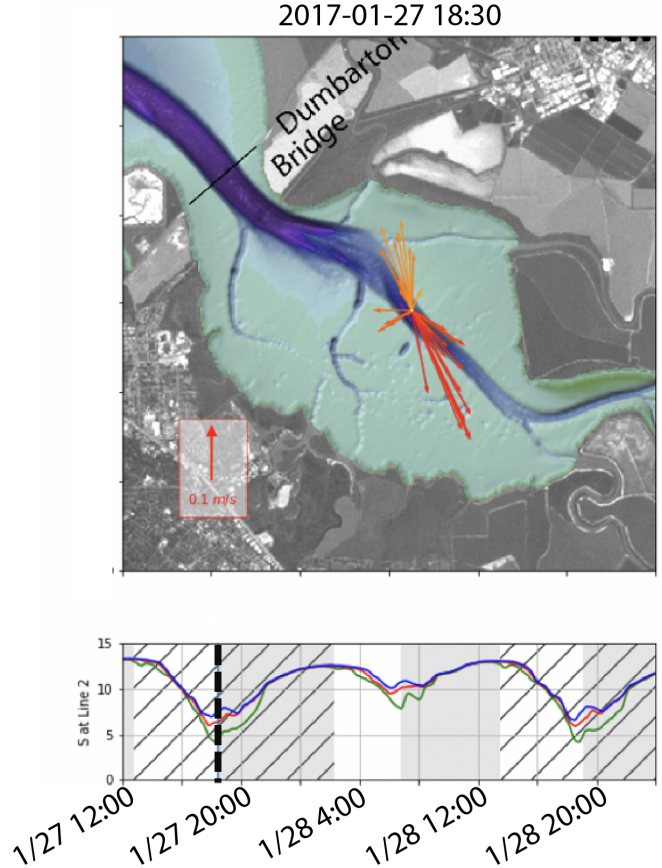

\section{B) Flood to Ebb}
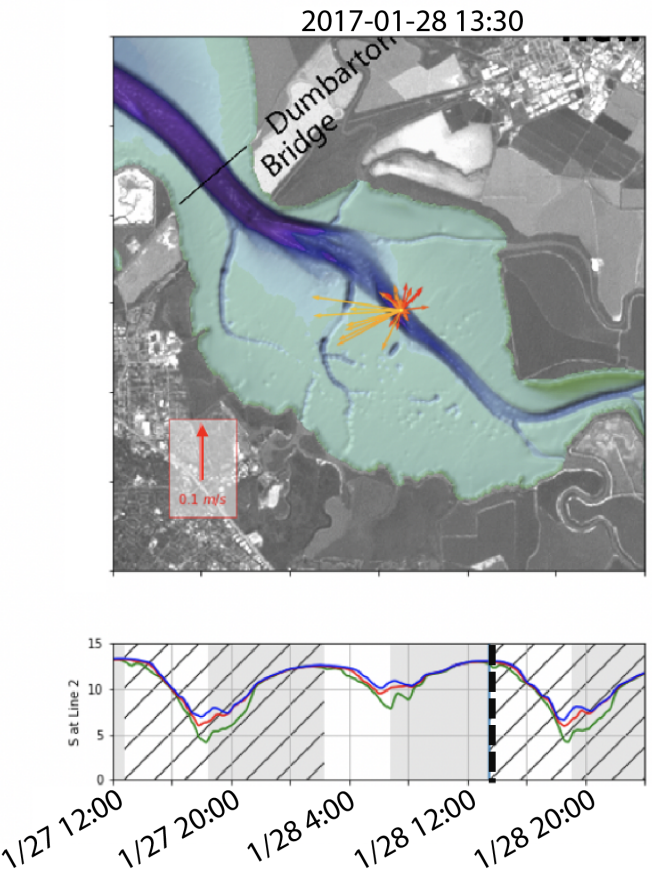

Bottom of water column

Figure 11: Velocity vectors at line 2 shows differences in lateral exchange flow patterns in the ebb to flood versus the flood to ebb tide transitions. Red arrows represent the bottom depth flows and the yellow arrows represent the top flow directions. (A) At the ebb to flood transition we see a pulse of lateral flow from the near bed shoal to the mid-column channel. Note the pictured longitudinal shear that occurs during this tidal transition. As the tide transitions from ebb to flood, the bottom reverses sign before the top. (B) At the flood to ebb transition we see a two-layer lateral exchange flow where the bottom is directed from the channel to the shoal and the flow at the top of the water column is directed from the shoal to the channel. Ebb tides correspond to white shading. Hatching refers to larger flood/ebb tides when there is a diurnal asymmetry.

The analysis of the previous section defines the tidal variability and relative magnitude of the various mechanisms responsible for stratification and destratification. Three terms, in addition to turbulent mixing, are important contributors: longitudinal straining, longitudinal advection and lateral straining (Figure 13). Longitudinal straining varies as would be expected under SIPS, in addition to a strong peak at the ebb-flood transition due to vertical phase lag in the tidal reversal. Longitudinal advection is important at this site due to the close proximity between the "mouth" at the Dumbarton Narrows and the shallow marsh perimeter. Energetic mixing at the Narrows creates strong along-axis gradients in stratification, with less stratified conditions down estuary that are tidally-advected along the estuarine channel, contributing strongly to the variability of stratification in the chan- 
nel. Finally, lateral straining is an important contributor to channel stratification dynamics, but with a complex tidal variability created by the interplay between differential advection, which creates lateral density gradients, and turbulent mixing, which inhibits the development of lateral circulation. This last element is similar to the conditions studied by Lacy et al. [Lacy et al., 2003], and just as in that case, the lateral straining produces stratification late in the flood tide that would never be predicted by traditional SIPS frameworks.

Figure 11 illustrates the difference in lateral exchange at the ebb to flood versus the flood to ebb transitions. The lateral exchange at the ebb to flood transition is much smaller in magnitude, occurring in the middle of the water column, and has limited lateral shear. At line 2, the lateral flows are all in one direction, from the shoals towards the channel. There is also a vertical lag in the reversal of longitudinal flow at the transition from ebb to flood. In contrast, on the flood to ebb transition, the lateral exchange has high shear with the bottom lateral velocities traveling from the channel towards the shoal and the top lateral velocities at higher magnitude going from the shoal towards the channel. The twolayer lateral profile is expected for lateral flows that are baroclinically driven. The differences in the lateral flows can also be seen in the salinity signature at each tide transition (Figure 2, e.g.). In the ebb to flood salinity time series, there is an increase in salinity at all sensors due to the more saline waters in the shoal being barotropically pushed into the channel. In the flood to ebb transition, the fresher shoal water is being transferred to the top of the channel, resulting in the freshening of the top sensor at line 2.

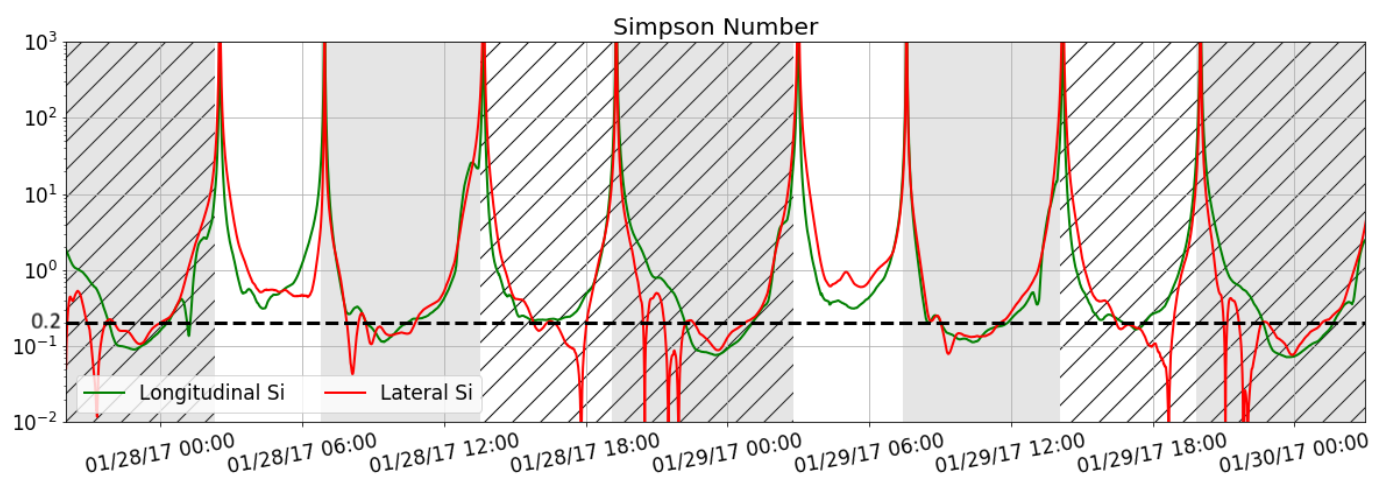

Figure 12: Longitudinal (green) and lateral (red) Simpson Numbers at line 2 [Lerczak and Geyer, 2004]. The larger the value of the Simpson number, the more likely the water column is to stratify. Note: Flood tides correspond to gray shading. Ebb tides correspond to white shading. Hatching refers to large flood/ebb tides when there is a diurnal asymmetry.

The longitudinal and lateral Simpson numbers shown in Figure 12. The longitudinal Simpson number was calculated using equation 2 where $u_{*}^{2}$ is calculated as $0.0025 u_{a v g}^{2}$. The lateral Simpson number is calculated using the following equation,

$$
S i_{y}=\frac{g \beta \frac{\partial S}{\partial y} H^{2}}{u_{*}^{2}}
$$

During the small ebbs (unhatched, white sections) we see the most potential for stratification. The small ebbs do not have as much breakdown of stratification (remains above 0.2 ) whereas the large ebbs drop below 0.2 in the mid-late ebb. These instances where we see the Simpson number drop below 0.2 in the mid-late ebb corresponds to the times we observed mid-ebb destratification in Figure 3. When approaching the slack tide, there is a drop in turbulent mixing (scaled by $\frac{1}{0.0025 u_{a v g}^{2}}$ ). The large Simpson number during slack tides indicates likely stratification. Therefore, small ebbs and slack tides are more likely to 
stratify. The lateral Simpson number has a similar pattern and magnitude to the longitudinal Simpson number which emphasizes the importance of lateral density forcing. There are even times, such as the small ebb tide on January 29, 2017, where the lateral Simpson number exceeds the longitudinal Simpson number by a factor of 2 .

The aggregation of longitudinal straining, longitudinal advection, lateral straining, and lateral advection are shown in Figure 8, including a comparison with the measured $\frac{\partial S_{z}}{\partial t}$. The creation of stratification over the ebb tides is captured well in time and magnitude. In contrast, the two negative destratification peaks at the beginning of the flood are not captured by the calculated $\frac{\partial S_{z}}{\partial t}$. Longitudinal advection does produce a significant destratification early in the flood, but occurs later in the flood tide and is more dispersed than the directly observed destratification. The most likely explanation of this difference is the presence of two frontal features that each reduce the stratification as they advect past the station. By using differences to estimate the longitudinal gradient, we underestimate the gradient, resulting in a more dispersed advective feature.

Totaling all the terms confirms overstraining is occurring in the late flood tides. Figure 13 shows that longitudinal straining and lateral straining are mostly responsible for the creation of stratification at the end of the ebb tide, and longitudinal advection and lateral straining are responsible for the destratification over the flood tide.

\subsection{Details of Tidal Dynamics}

\section{Ebb Tide}

At the beginning of the ebb tide, we see salinity beginning to drop and a sheared velocity profile. As we progress to the middle of the ebb tide, there is a creation of stratification with a quick breakdown of stratification when the tidal velocity is at a maximum. This breakdown is likely due to turbulent mixing. Over the ebb tide, longitudinal advection tightens isohaline lines, advecting a more stratified water column from the perimeter to the central site. From the middle of the ebb tide until the end of the ebb tide, longitudinal straining contributes to the creation of stratification. As shown in Figure 14, it appears longitudinal advection, longitudinal straining and lateral straining are activated at the same time. The shear in the lateral velocity (Figure 7) reaches a maximum in the mid-ebb tide resulting in a large contribution of lateral straining. This lateral strain occurs before the lateral salinity gradient has reversed meaning the shoal water that is brought into the channel is fresher than the channel adding to the creation of stratification in mid-ebb. At the same time, longitudinal straining is also contributing to the creation of stratification from mid-late ebb. Even though longitudinal straining is overall dominant in creating stratification over the ebb tide, the contribution of lateral straining is significant at the very beginning of the ebb tide and over mid-late ebb.

\section{Ebb to Flood Transition}

As the tide transitions from late-ebb to early-flood, salinity increases in the top, middle, and bottom of the water column. Longitudinal straining causes further development of stratification during this transition as the bottom velocity continues in the ebb direction and the top of the water column reverses to the flood direction resulting in maximum longitudinal shear. Differential advection causes the channel to be fresher than the shoal explaining why we see an increase in salinity in the water column at the ebb to flood transition. This increase in salinity also corresponds to a further increase in stratification. It should be noted that the strength of lateral circulation does not correspond with the strength of the lateral density gradient. The lateral density gradient is greatest at the end of the flood tide and the maximum measured lateral circulation was found at the end of the ebb tide. Maximum lateral circulation at the end of the ebb tide is due to decreasing turbulence due to reduced tidal velocity magnitudes and ambient stratification. During 

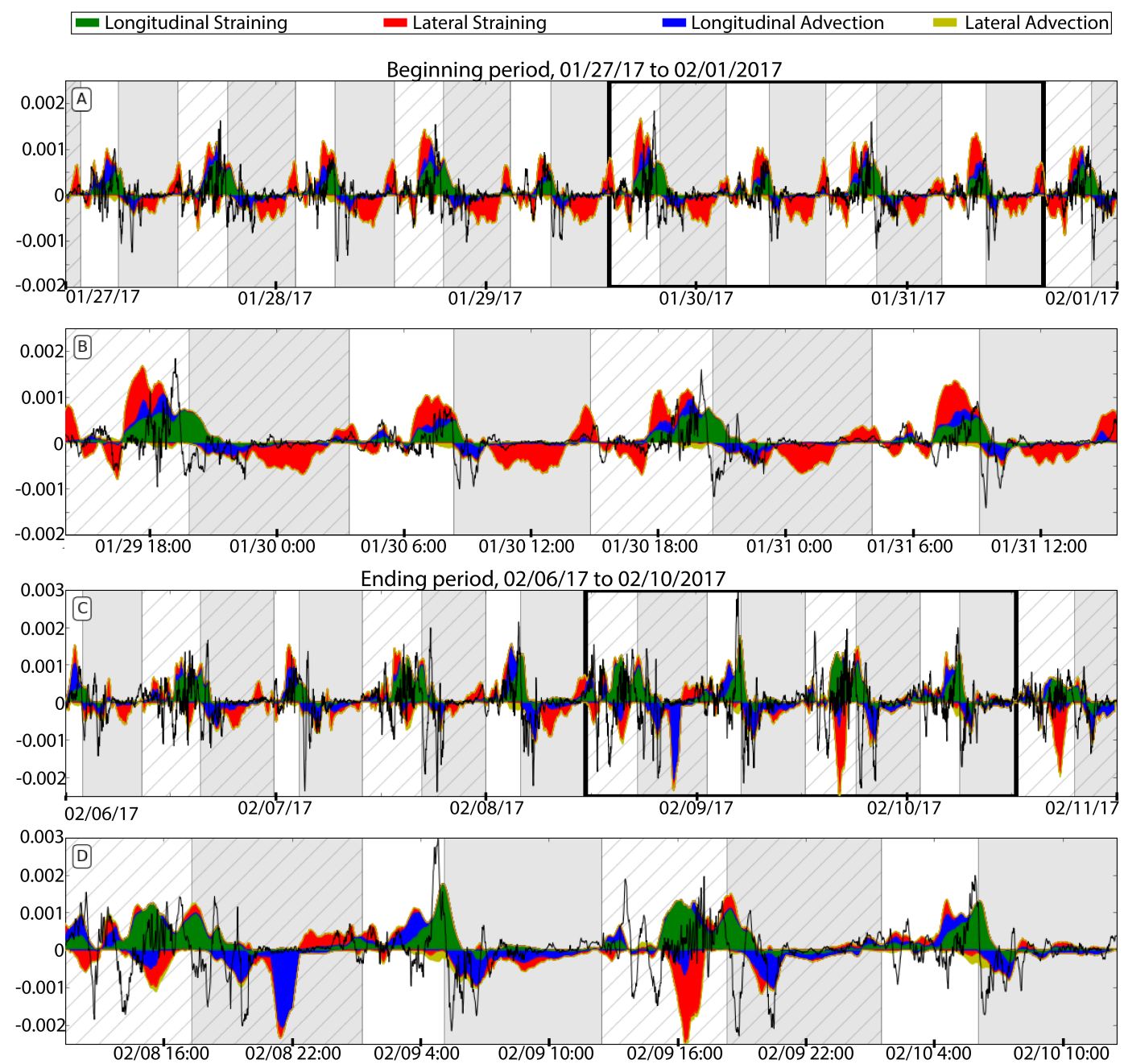

Figure 13: Fill plot of measured versus calculated $\frac{\partial S_{z}}{\partial t}\left[\frac{P S U}{S}\right]$. Note the vertical distance shown for each color is the contribution of that term. The areas are not overlaid, so the magnitude of lateral straining is added onto the area of longitudinal straining, not behind. The positive area has not had the negative area subtracted from it. By adding the positive area and the negative area at each time step, you would get the blue lines shown in Figure 8. The measured value of $\frac{\partial S_{z}}{\partial t}$ is plotted in black. (A) Shows the first, dry spring tide. (B) Zooms into 4 tidal cycles outlined by the black box in subplot A. (C) Shows the second, wet spring tide. (D) Zooms into 4 tidal cycles outlined by the black box in subplot $\mathrm{C}$.

this tide transition, we also see the reduction of the lateral baroclinic pressure gradient. Therefore, the lateral exchange at the transitions are driven by different forcings.

\section{Flood Tide}

Over the flood tide, salinity begins to increase. There is a more uniform longitudinal velocity. Stratification is broken down in two distinct instances. The first destratification event was not captured in the measurements suggesting it is due to a frontal feature that is not captured in the spatial resolution of the lines that were set. The second destratification event is due to longitudinal advection bringing more well-mixed water from the narrows. As the flood tide persists, there is little longitudinal or lateral shear. From mid-late flood, lateral straining contributes to overstraining which results in increased mixing. 


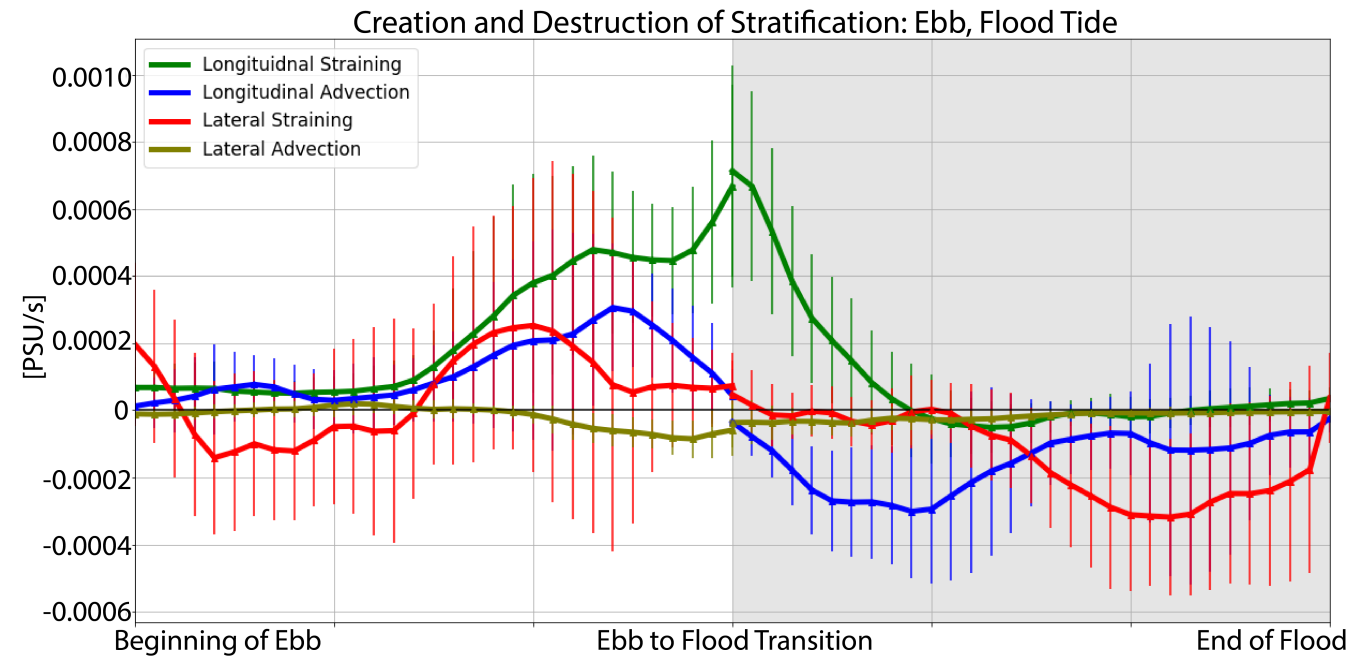

Figure 14: Tidal phase averaged calculated longitudinal straining, longitudinal advection, lateral straining, and lateral advection. Longitudinal gradients were calculated using lines 1 and 3 to estimate and lateral gradients using lines 2 and 6 . The first half shows tidally-averaged values over the ebb tide, and the second half in gray shows tidally-averaged values over the flood tide. Longitudinal straining works to create stratification from mid-ebb until mid-flood. Longitudinal advection creates stratification at the end of the ebb tide and then works to destratify at the beginning of the flood tide. Lateral straining becomes important at the end of the ebb tide and the end of the flood tide. At the end of the ebb tide, lateral straining creates stratification and over mid to late-flood lateral straining overstrains the water column inputting turbulent energy maintaining a homogeneous vertical salinity structure in the channel.

\section{Flood to Ebb Transition}

At the end of the flood tide, stratification begins to develop. Although the measured lateral velocity is low, we see that at the end of the flood tide is when we have the greatest lateral salinity gradient. At this time, the shoal is fresher than the channel (opposite from the lateral salinity gradient at the end of the ebb tide). Looking at the salinity pattern in the top, middle, and bottom of the water column in Figure 2, we see a pulse of freshwater at the surface. Right at the beginning of this pulse, we see that there is a twolayer lateral velocity profile with the bottom of the water column pulling channel water towards the shoal and the top of the water column pulling shoal water towards the channel. The deviation of the top salinity from the bottom salinity results in the creation of stratification at the flood to ebb transition.

\section{Concluding Remarks}

Observations in Lower South San Francisco Bay illustrated the tidal variations of stratification, including an evaluation of the responsible mechanisms. The most significant stratification event occurs at the ebb-flood transition due to a combination of longitudinal straining and longitudinal advection. Further stratification was developed at the beginning of the flood tide due to a vertical shear created by a phase lag in the tidal velocities. The most important destratification period is the early flood tide, during which a sequence of mechanisms is found to be responsible. First, a pulse of saline water is received in the top, middle, and bottom of the channel water column. Next, longitudinal advection carries progressively less stratified water masses into the observed water column, and the observa- 
tions seem to indicate passage of two strong frontal transitions during this period. Finally, throughout the flood tide, longitudinal straining works to reduce the stratification; once the water column is destratified, it produces turbulent mixing through overstraining.

Stratification dynamics switch between being longitudinally dominated during the middle of ebb and flood tides to being laterally dominated during the tidal transitions. Differential advection along with lateral exchange at tide transitions resulted in more saline water transported from the shoals to the channel at the end of each ebb tide from barotropic forcing and less saline water transported from the shoals to the top of the channel at the end of the flood tide from baroclinic forcing. Lastly, estimates of the impact of lateral advection on the creation or destruction of stratification were found to be insignificant compared to longitudinal mechanisms and lateral straining except briefly at the end of the ebb tide.

The variation of the lateral density gradient is not symmetric between ebb and flood, and the lateral density gradient is much smaller in magnitude at the end of the ebb tide than it is at the end of the flood. At the end of the flood tide, fresh water in the shoals exchange with a saline channel, which produce pulses of near-surface waters into the channel from the density-driven lateral exchange. At the end of the ebb tide, this structure is not reversed, and the lateral density gradients are quite small. The salinity structure shown at the central location suggests that the lateral exchange is driven by a cross-channel barotropic forcing at the end of the ebb tide which is difficult to see in the limited lateral velocity data in the shoals.

\section{Notation}

S Salinity

$S_{z}$ Stratification, $S_{b}-S_{t}$

b Bottom

t Top or Time

$x$ Direction along the channel, positive on flood tide (SE direction)

$y$ Direction perpendicular to the channel, positive in NE direction

$z$ Direction perpendicular to sea floor, zero at sea floor and positive upwards mm Millimeters

s Seconds

PSU Practical Salinity Unit

u Longitudinal velocity, velocity in the $\mathrm{x}$-direction

$\mathbf{v}$ Lateral velocity, velocity in the y-direction

w Vertical velocity, velocity in the z-direction

$\boldsymbol{v}_{\boldsymbol{T}}$ Turbulent diffusivity based on the tidal velocities

$\boldsymbol{u}_{*}$ Friction Velocity

$\beta$ Saline Contractivity

$\boldsymbol{K}_{\boldsymbol{Z}}$ Vertical mixing coefficient of a scalar

E Representation of a mixing coefficient

Si Longitudinal Simpson Number

$S \boldsymbol{i}_{\boldsymbol{y}}$ Lateral Simpson Number

$b_{x}-$

H Water depth

$\boldsymbol{C}_{\boldsymbol{D}}$ Coefficient of drag

$U_{\boldsymbol{C}}$ Channel velocity

$U_{S}$ Shoal velocity

$\boldsymbol{u}_{\text {tide }}$ Tidal velocity amplitude

$\boldsymbol{u}_{\boldsymbol{S}}$ Shoal velocity amplitude

$\omega \frac{2 \pi}{\text { Tidal Period }}$ 
g Gravitational Acceleration

$\boldsymbol{L}_{\boldsymbol{y}}$ Lateral length scale, half of estuary width

\begin{abstract}
Acknowledgments
Thanks to the San Francisco Bay Nutrient Management Strategy and National Science Foundation (NSF) or funding support work. A special thank you to Francis Parchaso and Sarah Pearson United States Geological Survey (USGS) for the in-kind financial and physical support required to accomplish this field work and analysis and Rachel Allen at UC Berkeley for the accompaniment and strength required to cycle this deployment over the past year. Data presented in this manuscript are available at https://doi.org/10.6078/D14H5K.
\end{abstract}

\title{
References
}

Becherer, J., M. Stacey, L. Umlauf, and H. Burchard (2014), Lateral circulation generates flood tide stratification and estuarine exchange flow in a curved tidal inlet, Journal of Physical Oceanography, 45, 638-656.

California Department of Water Resources (), California Irrigation Management Information System (CIMIS), http: //www . cimis . water . ca.gov/, [Online; accessed 201704-15].

Cloern, J. E., N. Knowles, L. R. Brown, D. Cayan, M. D. Dettinger, T. L. Morgan, D. H. Schoellhamer, M. T. Stacey, M. van der Wegen, R. W. Wagner, and A. D. Jassby (2011), Projected evolution of california's San Francisco bay-delta-river system in a century of climate change, PLoS ONE, 6(9).

Foxgrover, A. C., B. E. Jaffe, G. T. Hovis, C. A. Martin, J. R. Hubbard, M. R. Samant, and S. M. Sullivan (2007), 2005 hydrographic survey of South San Francisco Bay, California, U.S. Geological Survey Open-File Report, p. 1169.

Geyer, W. R., and P. MacCready (2014), The estuarine circulation, Annual Review of Fluid Mechanics, 46, 175-197.

Geyer, W. R., J. Trowbridge, and M. Bowen (2000), The dynamics of a partially mixed estuary, Journal of Physical Oceanography, 30, 2035-2048.

Huzzey, L., and J. Brubaker (1988), The formation of longitudinal fronts in a coastal plain estuary, Journal of Geophysical Research, 93(C2), 1329-1334.

Jay, D., and J. D. Smith (1990), Circulation, density distribution and neap-spring transitions in the Columbia River Estuary, Progress in Oceanography, 25, 81-112.

Lacy, J., M. Stacey, J. Burau, and S. Monismith (2003), Interaction of lateral baroclinic forcing and turbulence in an estuary, Journal of Geophysical Research, 108(C3), 34-134-15.

Lerczak, J., and W. R. Geyer (2004), Modeling the lateral circulation in straight, stratified estuaries, Journal of Physical Oceanography, 34, 1410-1428.

Lucas, L., J. Koseff, J. Cloern, S. Monismith, and J. Thompson (1999), Processes governing phytoplankton blooms in estuaries. i: The local production-loss balance, Marine Ecology Progress Series, 187, 1-15.

Nepf, H.-M., and W. R. Geyer (1996), Intratidal variations in stratification and mixing in the Hudson estuary, Journal of Geophysical Research, 101(C5), 12,079-12,086.

Ruskin (), RBRduo and RBRconcerto, https://rbr-global.com/products/ standard-loggers/rbrduo-ct, [Online; accessed 2018-04-15].

Schoellhamer, D. H. (2011), Sudden clearing of estuarine waters upon crossing the threshold from transport to supply regulation of sediment transport as an erodible sediment pool is depleted: San Francisco bay, 1999, Estuaries and Coasts, 34, 885-899.

Scully, M., and W. R. Geyer (2012), The role of advection, straining, and mixing on the tidal variability of estuarine stratification, Journal of Physical Oceanography, 42, 855868. 
Scully, M. E., and C. T. Friedrichs (2007), The importance of tidal and lateral asymmetries in stratification to residual circulation in partially mixed estuaries, Journal of Physical Oceanography, 37(6), 1496-1511.

Seabird Scientific (), SBE 37-SM MicroCAT C-T (P) Recorder, http://www . seabird. com/sbe37sm-microcat-ctd/, [Online; accessed 2018-04-15].

Simpson, J.-H., J. Brown, J. Matthews, and G. Allen (1990), Tidal straining, density currents, and stirring in the control of estuarine stratification, Estuaries, 13(2), 125-132.

Stacey, M., J. Burau, and S. Monismith (2001), Creation of residual flows in a partially stratified estuary, Journal of Geophysical Research, 106(C8), 17,013-17,037. 

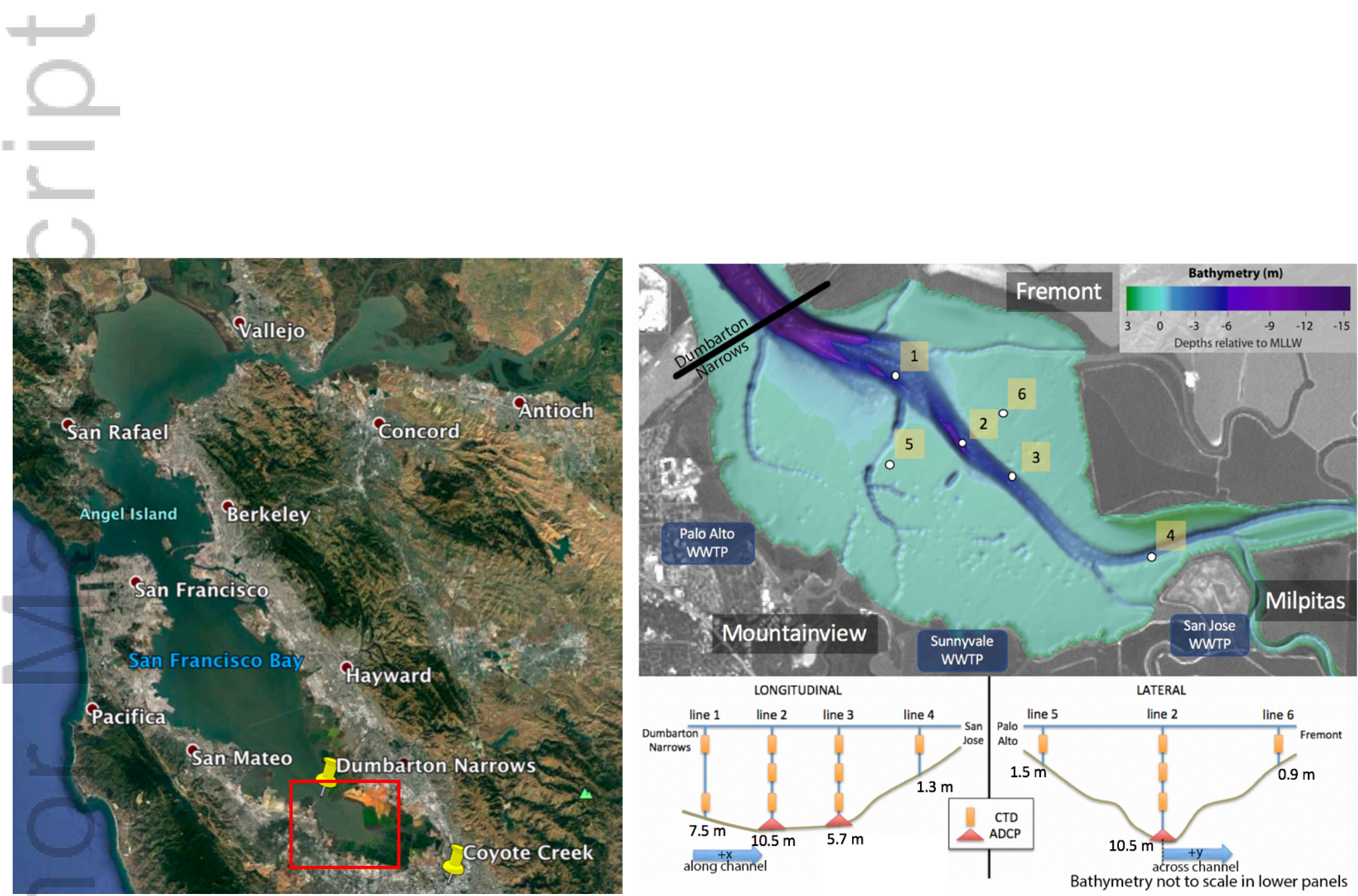

2019JC014980-f01-z-.png

This article is protected by copyright. All rights reserved. 
Line 2 Salinity and Precipitation: January 27, 2017 - February 11, 2017

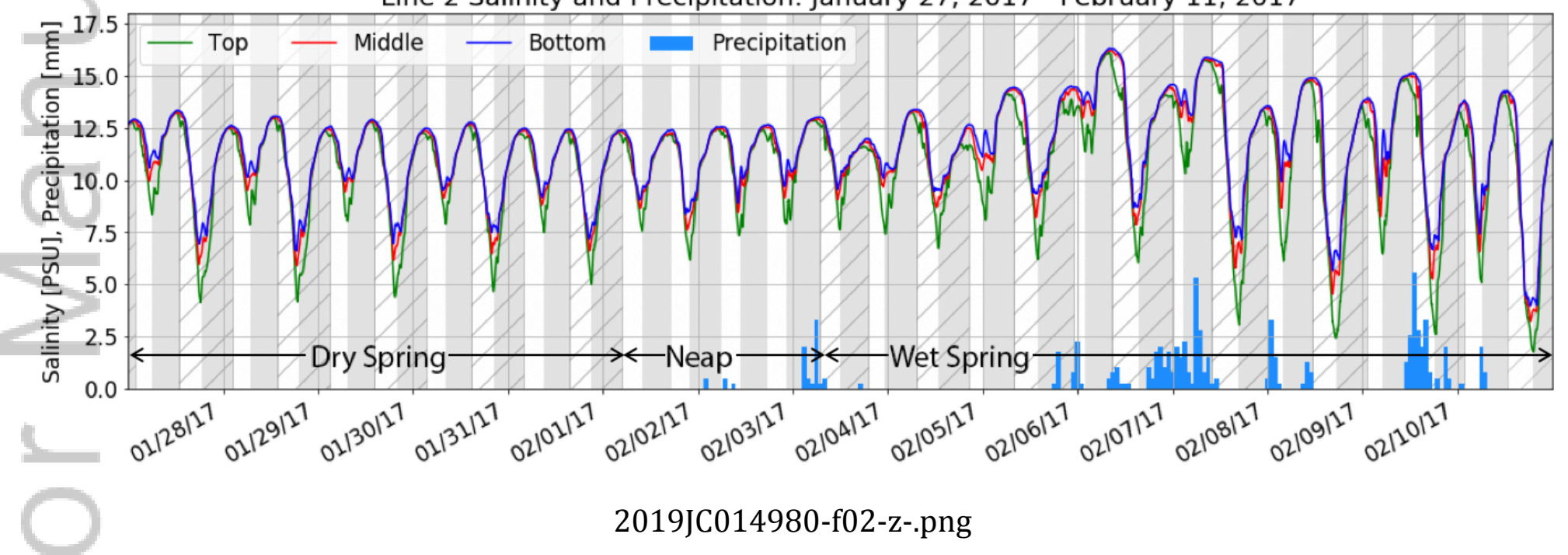

This article is protected by copyright. All rights reserved. 
Stratification, $S_{z}, 30$ minute averaged
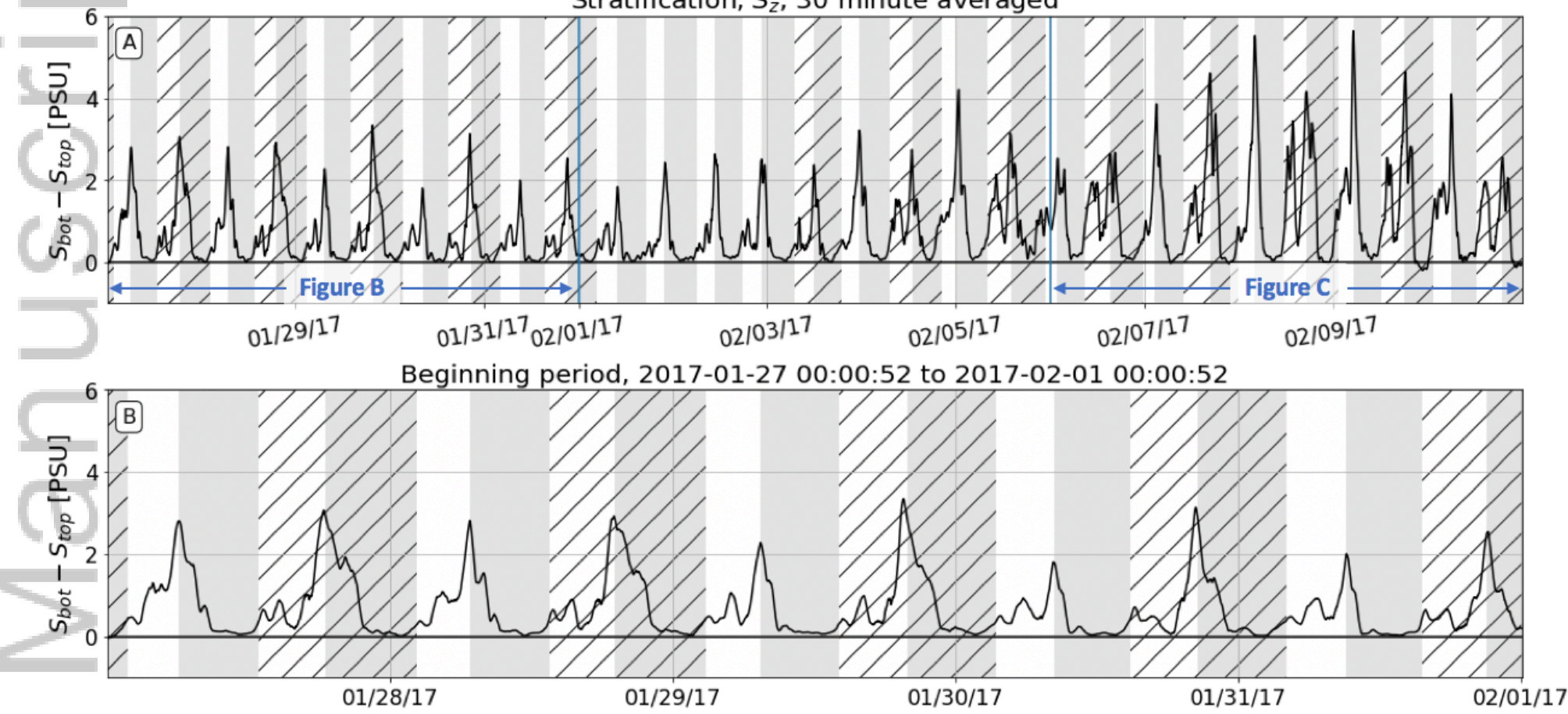

Ending period, 2017-02-06 00:00:52 to 2017-02-10 23:59:52

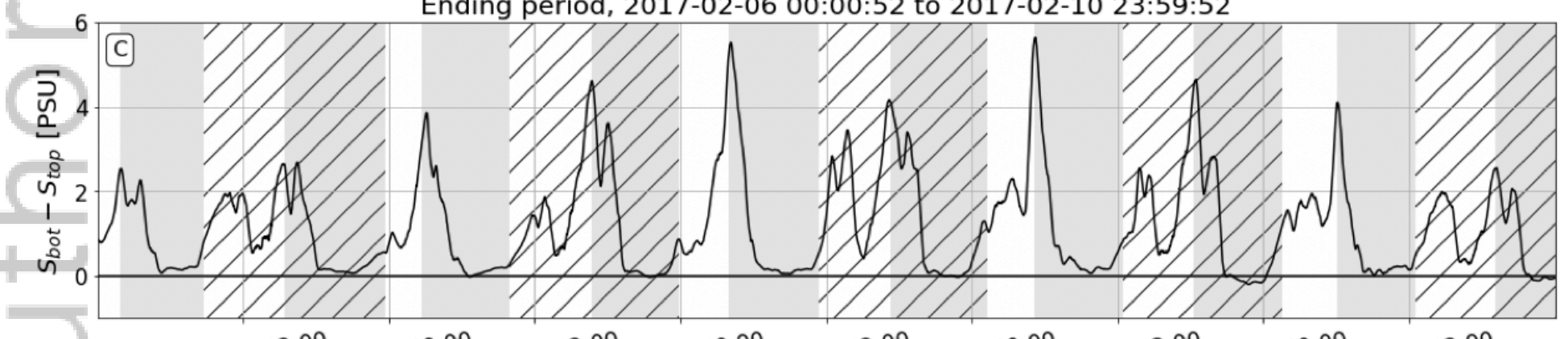

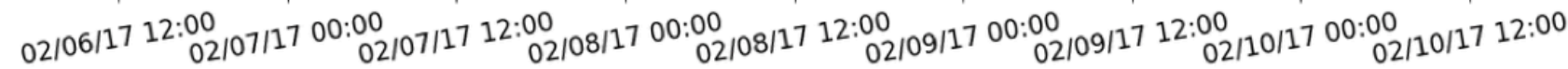

2019JC014980-f03-z-.png

This article is protected by copyright. All rights reserved. 
Average Longitudinal Gradient, Calculated using measurements at lines 1 and 3
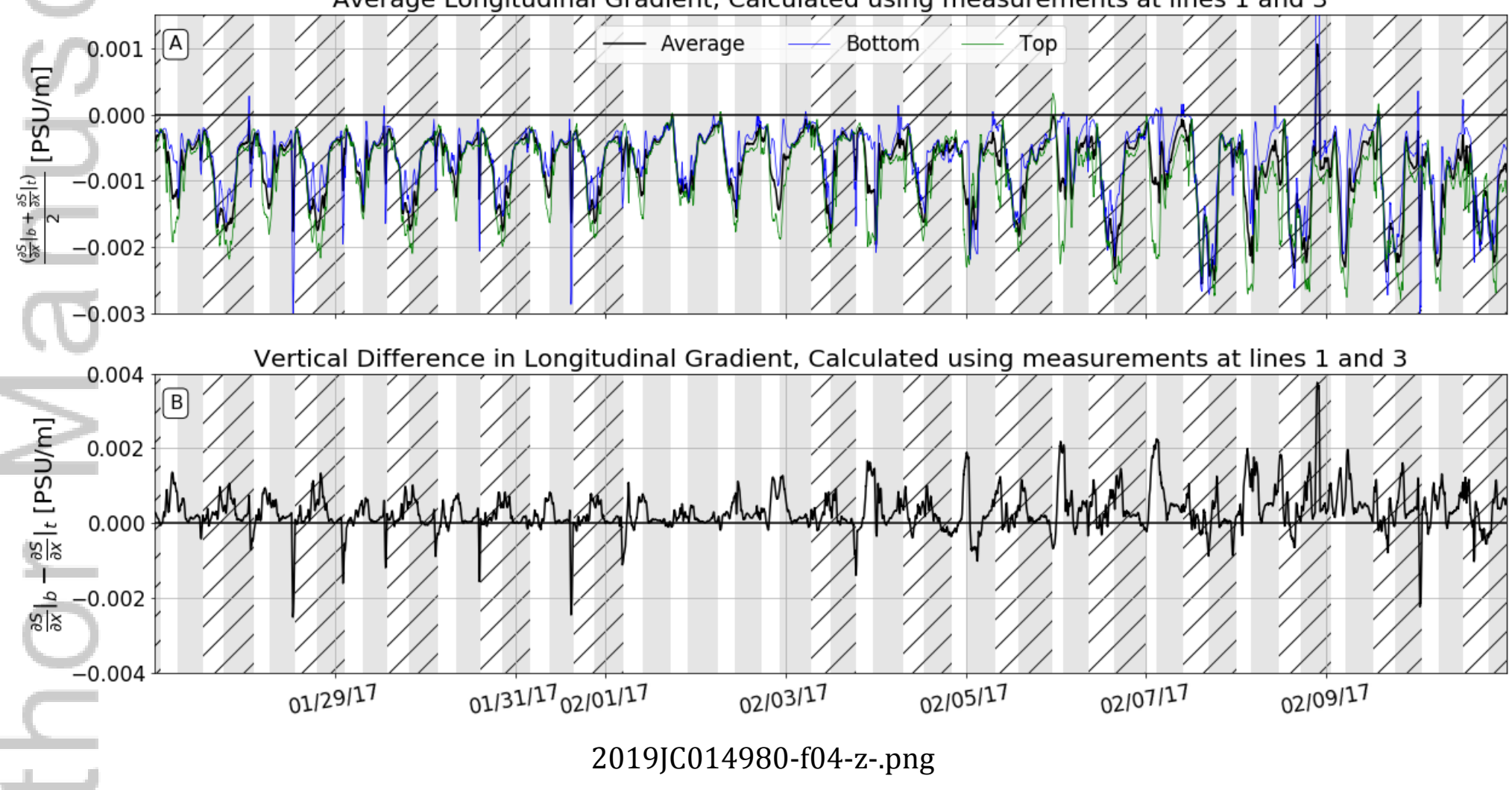

This article is protected by copyright. All rights reserved. 
Lateral Gradient, Calculated using measurements at lines 2 and 6

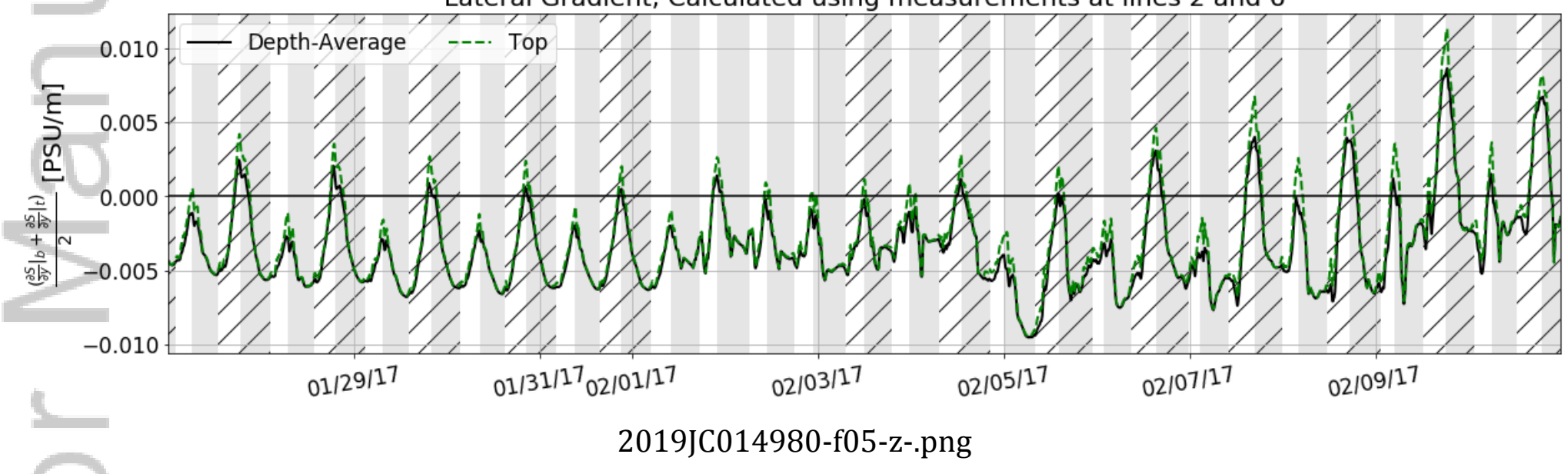

This article is protected by copyright. All rights reserved. 
$u_{\text {top }} \& u_{\text {bottom }}$
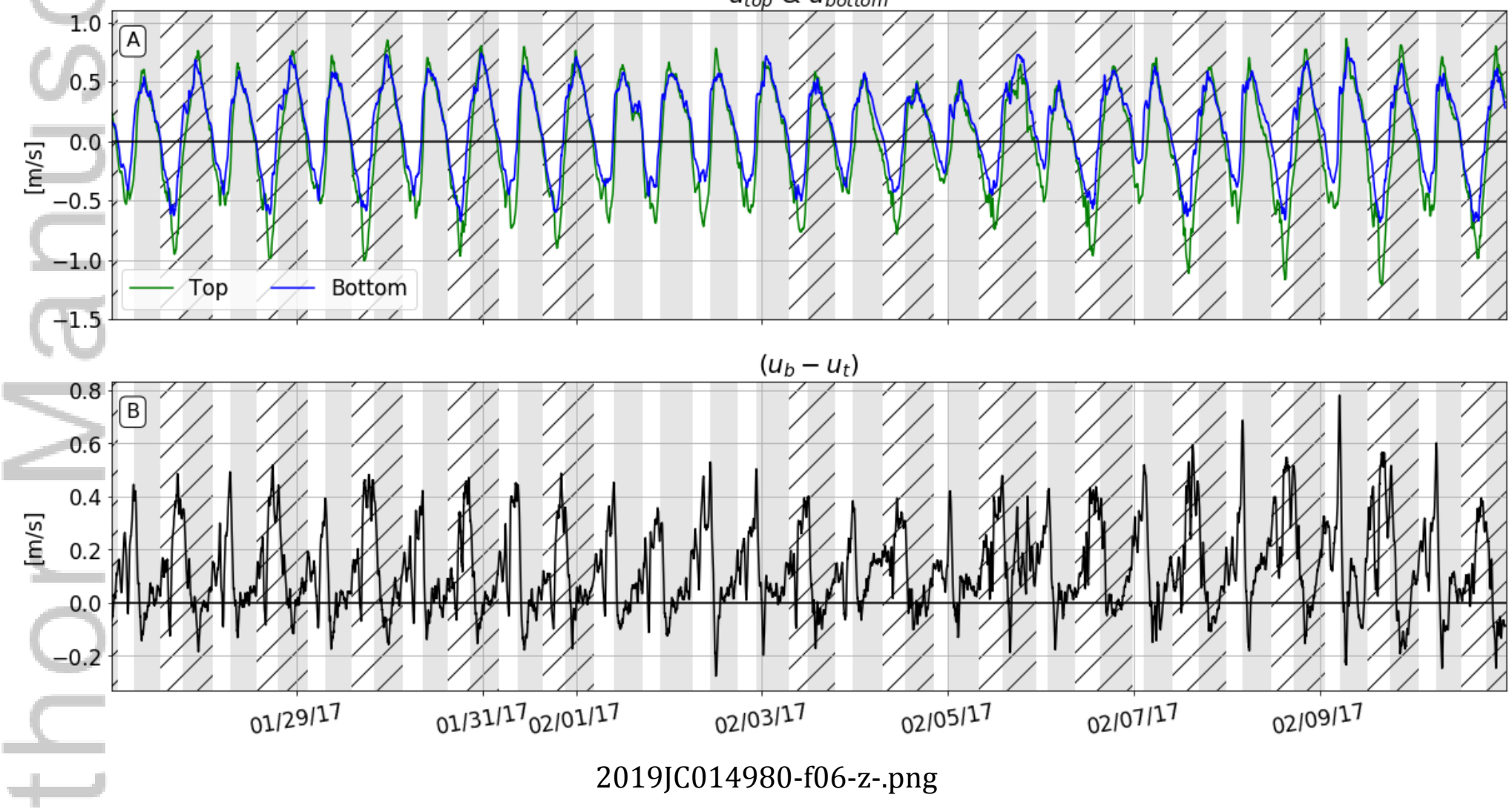

This article is protected by copyright. All rights reserved. 
$v_{\text {top }} \& v_{\text {bottom }}$
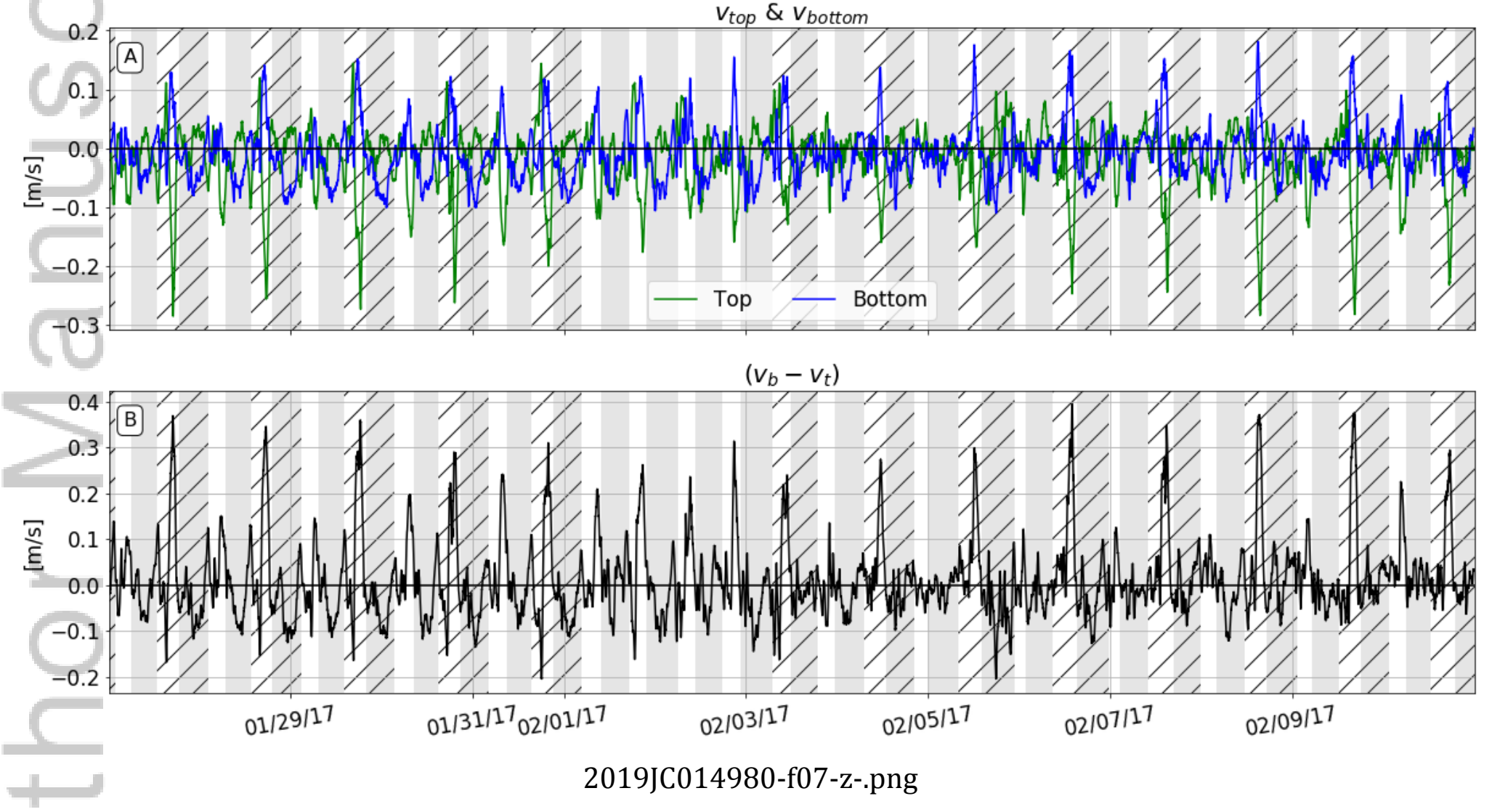

This article is protected by copyright. All rights reserved. 
Measured versus Calculated $\mathrm{d} S_{z} / \mathrm{dt}$, Longitudinal Gradients Calculated using Lines 1 and 3, Lateral Gradients Calculated using Lines 2 and 6
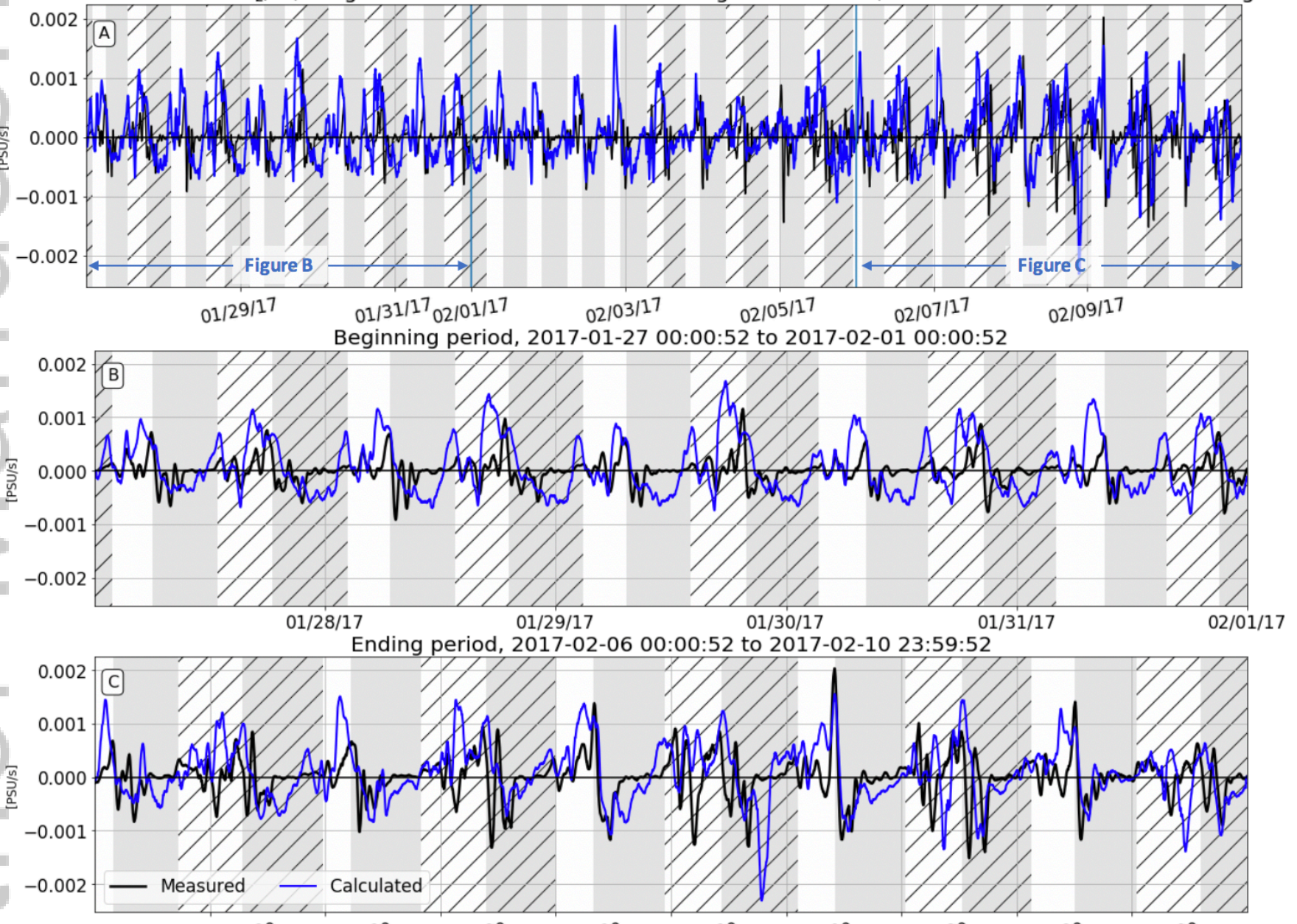

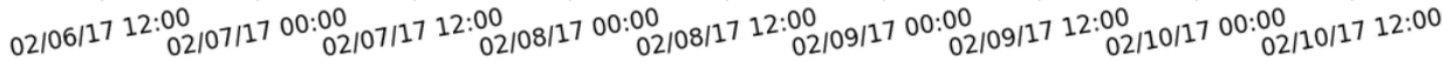

2019JC014980-f08-z-.png

This article is protected by copyright. All rights reserved. 


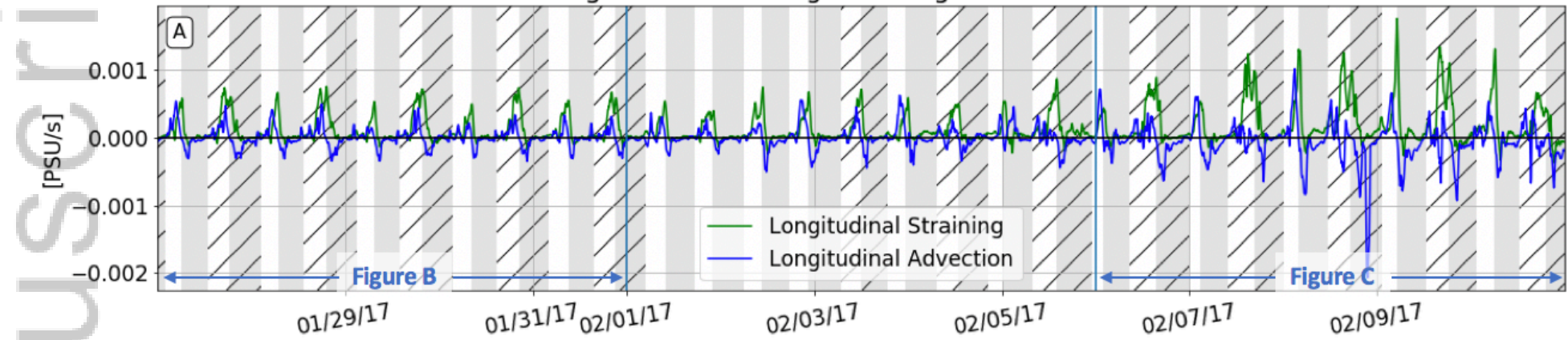

Beginning period, 2017-01-27 00:00:52 to 2017-02-01 00:00:52
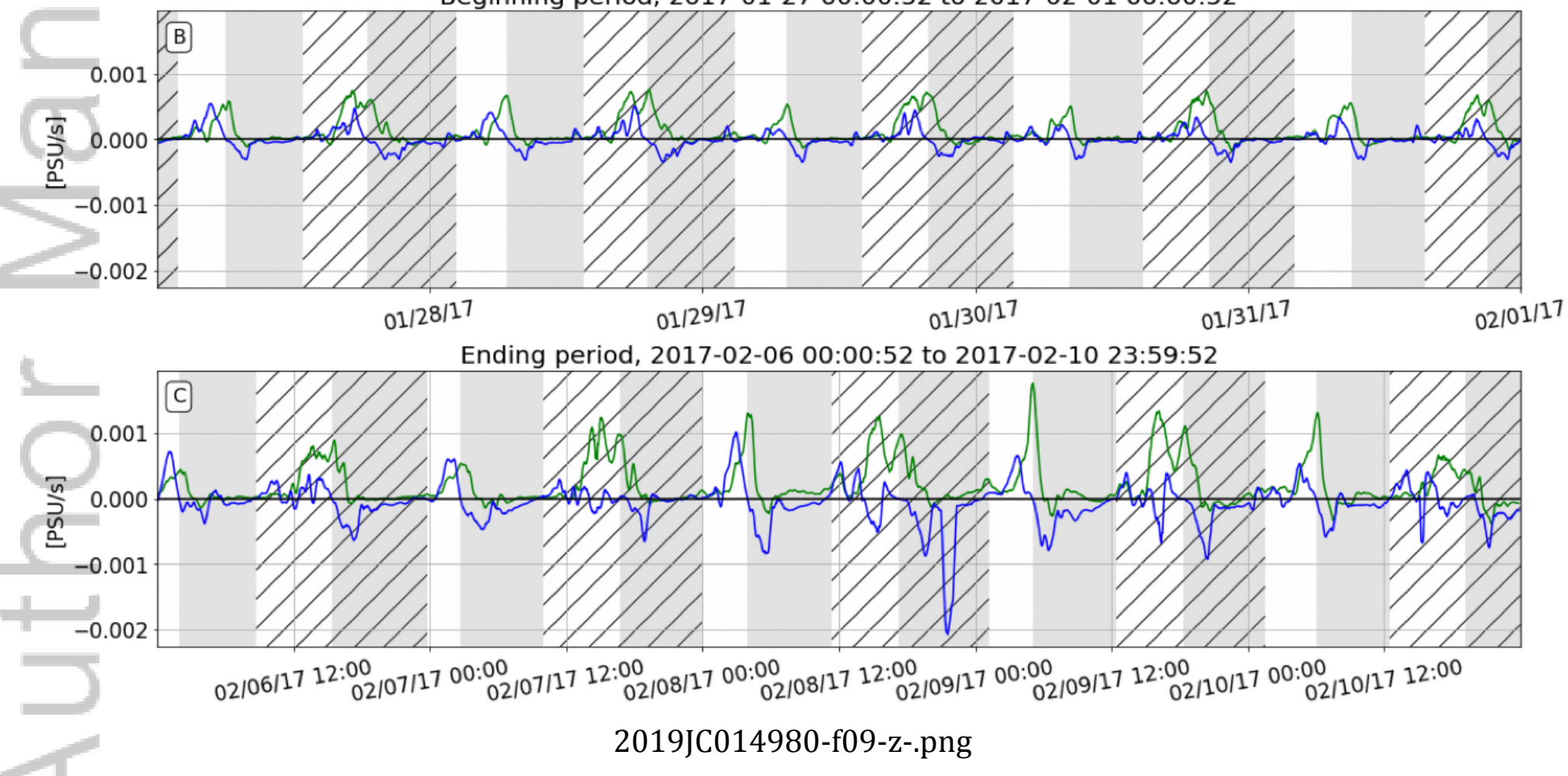

This article is protected by copyright. All rights reserved. 
A) Ebb to Flood

2017-01-27 18:30
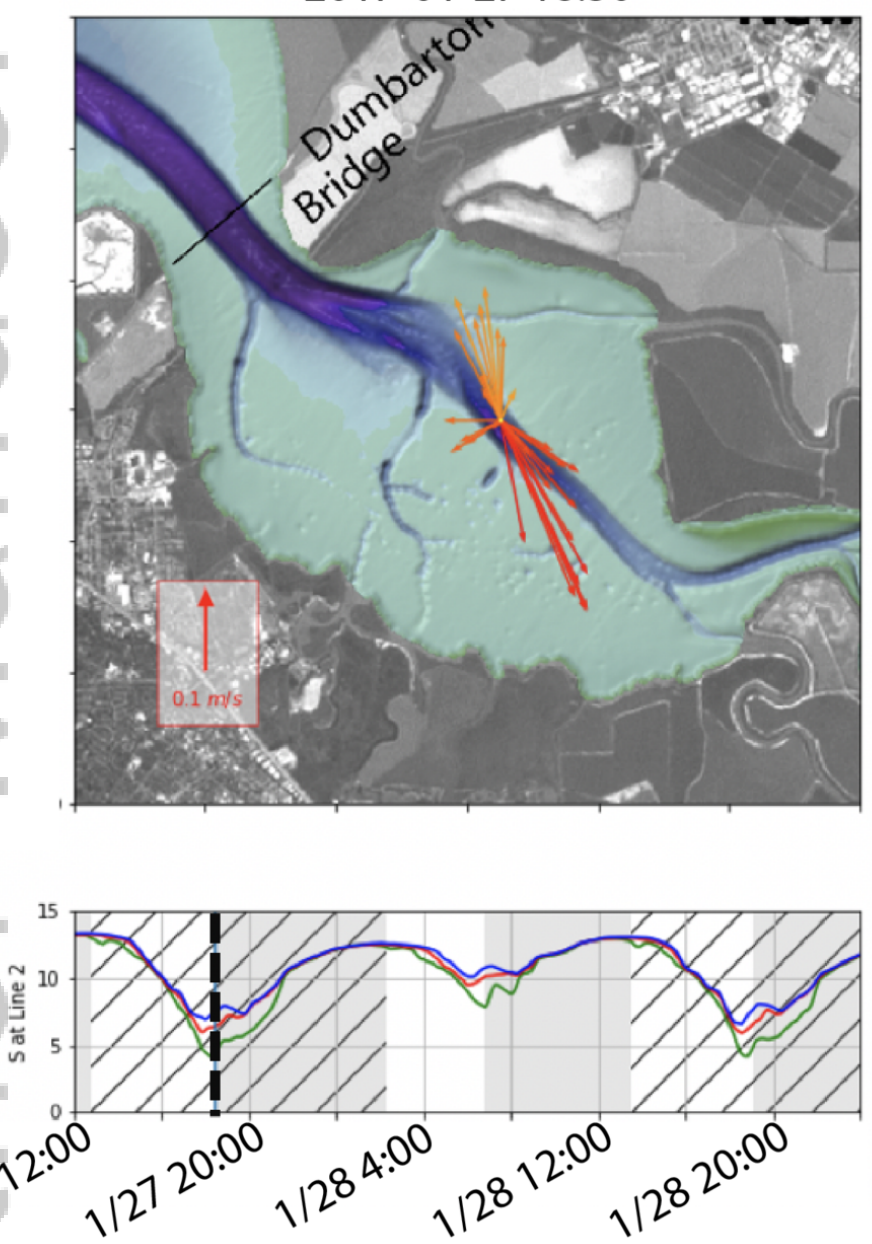

\section{B) Flood to Ebb}
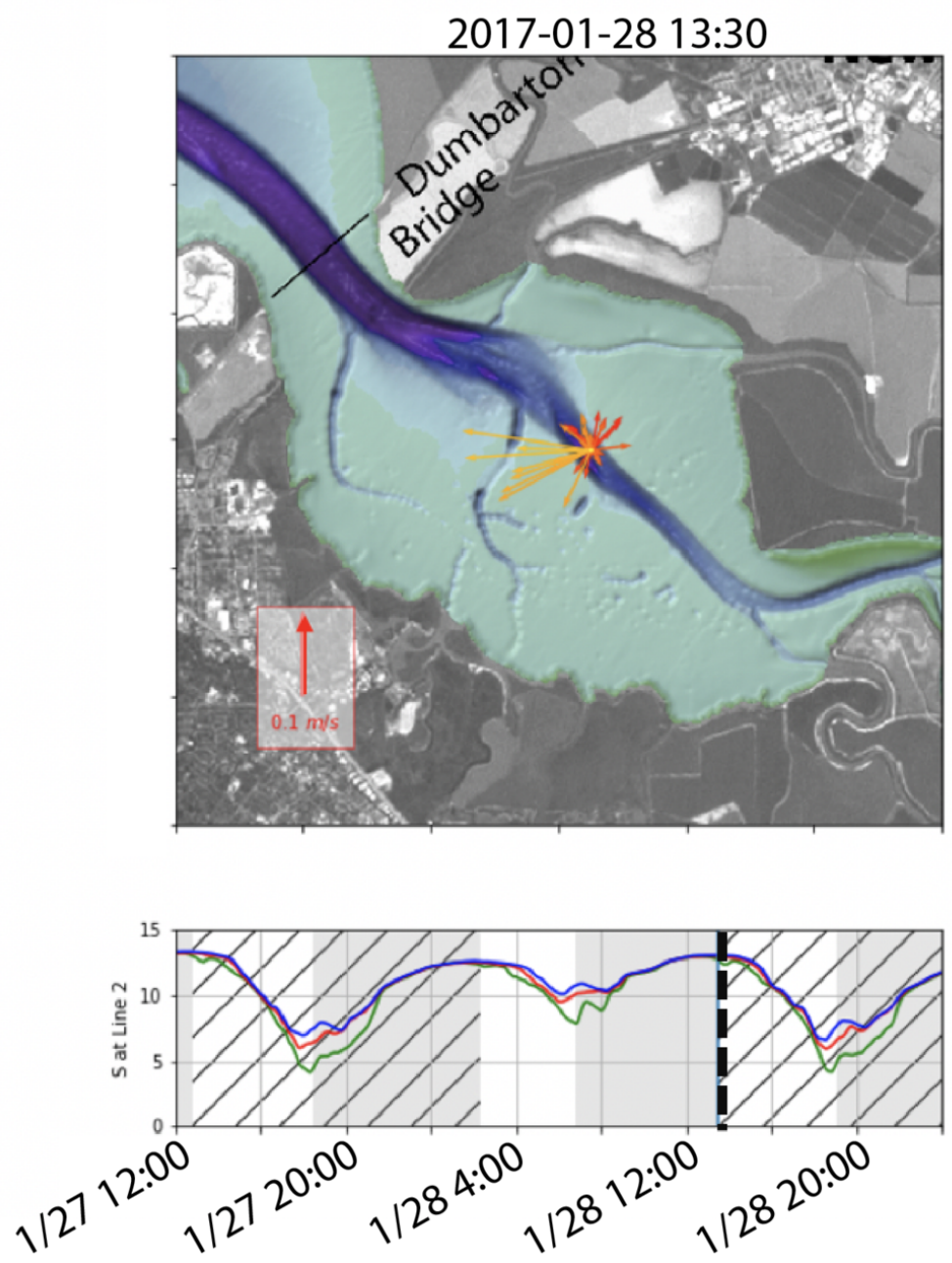
Creation and Destruction of Stratification: Ebb, Flood Tide

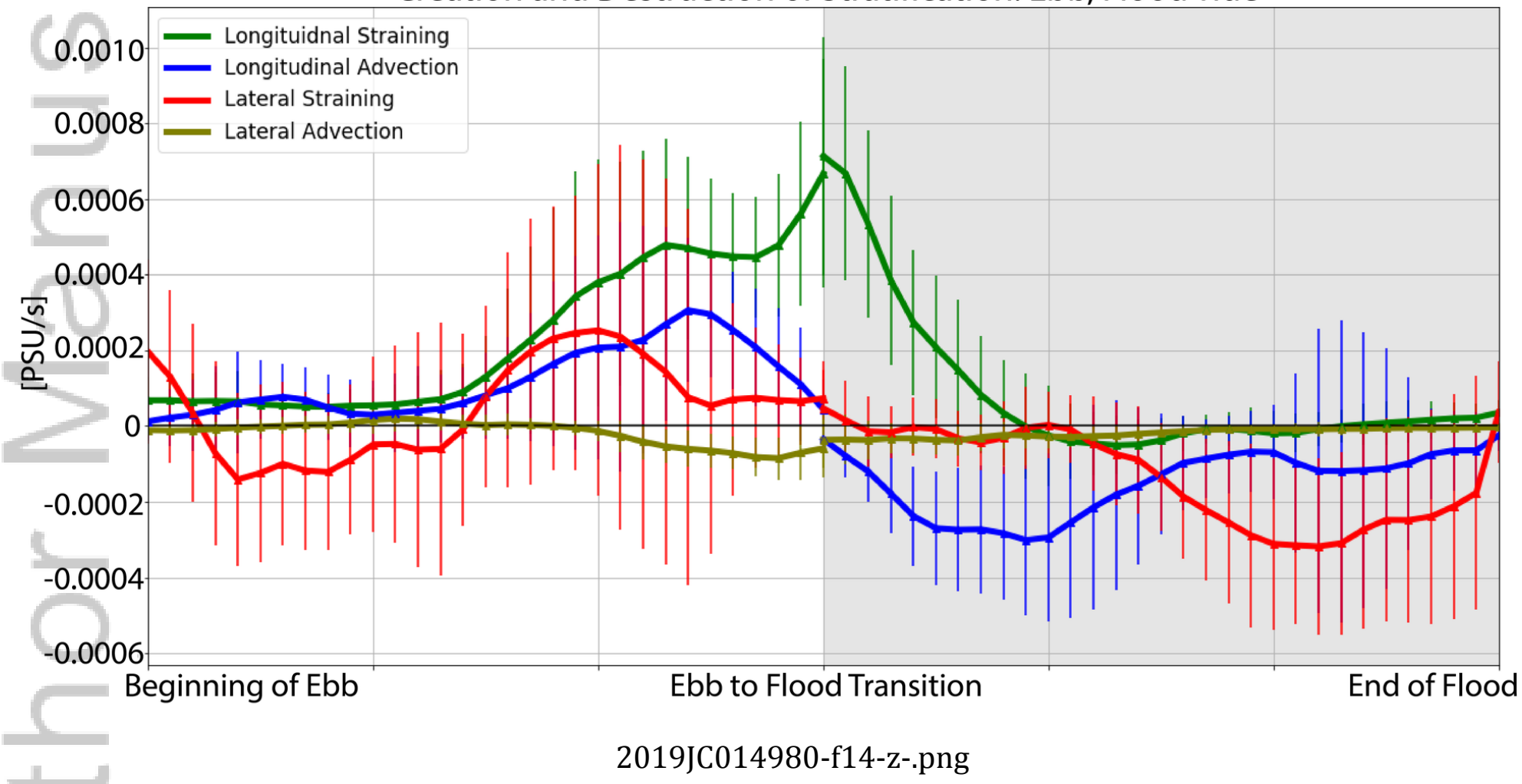

This article is protected by copyright. All rights reserved. 